\title{
Roll-to-roll fabrication of high surface area mesoporous carbon with process-tunable pore texture for optimization of adsorption capacity of bulky organic dyes
}

Zhe Qiang, Burcu Gurkan, Jianxing Ma, Xiangyu Liu, Yuanhao Guo, Miko Cakmak, Kevin A. Cavicchi and Bryan D. Vogt*

Department of Polymer Engineering, University of Akron, 250 S forge st, Akron, $\mathrm{OH}, 44325$

\begin{abstract}
Large-scale (multigram-to-kilogram) fabrication of soft-templated ordered mesoporous carbons $(\mathrm{OMC})$ is enabled by roll-to-roll (R2R) processing via evaporation induced self assembly of Pluronic F127, oligomeric phenolic resin (resol), and tetraorthosilicate (TEOS) from ethanolic solution. The solution concentration, TEOS loading (etchable for microporous framework), and crosslinking temperature impact the pore structure. Here we demonstrate that mesoporous carbons with surface areas up to $2455 \mathrm{~m}^{2} / \mathrm{g}$ can be obtained under the proper processing conditions. Transmission electron microscopy (TEM), smallangle X-ray scattering (SAXS) and nitrogen adsorption-desorption isotherms reveal (i) supressed framework shrinkage with increasing solution concentration during casting, (ii) improved long range order and higher surface area with increasing TEOS content up to 3:1 TEOS:resol, and (iii) enhanced porosity with crosslinking at $100^{\circ} \mathrm{C}$. These differences can be
\end{abstract}


explained on the basis of block copolymer thermodynamics and mechanical reinforcement by silica. This family of OMCs are effective adsorbents for bulky aqueous organic dyes, such as methylene green (MG) and methyl blue (MB), with high adsorption capacities of $0.436 \mathrm{~g}$ MG/g OMC and $0.378 \mathrm{~g} \mathrm{MB/g} \mathrm{OMC} \mathrm{obtained.} \mathrm{This} \mathrm{R2R} \mathrm{method} \mathrm{provides} \mathrm{a} \mathrm{facile} \mathrm{method} \mathrm{to}$ generate significant quantities of OMCs with tunable pore textures.

Keywords: ordered mesoporous carbon; FDU-15; soft templating; evaporation-induced self assembly

\section{Introduction}

Ordered mesoporous carbon (OMC) [1, 2] offers tremendous promise in a host of applications, such as energy storage as battery [3] or supercapacitor [4] electrodes, chemical separations as membranes [5] or absorbents [6], and electrodes in solar cells [7]. An efficient synthesis route for these OMCs is the "soft-templating" method that employs cooperative assembly of carbonizable precursors with amphiphilic block copolymers (BCPs) to generate the templated nanostructures $[8,9]$. Pyrolysis of the BCP-crosslinked precursor removes the template and provides a high carbon yield to generate a stable porous carbon . There are some advantages in terms of control of the pore structure using hard templating [10], such as colloidal silica templates [11]. However in both methods, small batch 
syntheses, which limits scale up potential, are typically utilized for the fabrication of templated ordered mesoporous carbons. For the scale-up of OMCs, Stein and coworkers demonstrated the use of a sucrose or $\mathrm{KCl}$ sacrifical layer significantly improves the carbon yield [12], but this method still tends to yield sub-gram quantities. To extend this idea, Zhao and coworkers demostrated that a sacrifical polyurethane (PU) foam scaffold [13] can generate kilograms of OMCs. Although successful, this method has several limitations associated with the evaporation of the templating solution and degradation by-products of the PU scaffold during pyrolysis. In particular, slow evaporation prevents rapid synthesis and can lead to phase separation for multicomponent coassembly, such as in the tri-constituent co-assembly approach to fabricate OMC-silica nanocomposites [14]. The etching of silica from these composites introduces the micropores in the carbon wall, which significantly increases the surface area of the OMC [15]. These high surface area OMCs could have high utility in a number of applications, such as catalysis and batteries $[16,17]$. Therefore, the development of a scalable fabrication method would improve the commercial viability of these high surface area mesoporous OMCs.

Roll-to-roll (R2R) processing is an enabler of low-cost contiuous fabrication of functional materials, including flexible electronics [18], electrode materials [19], organic photovoltaics [20], and nanoimprinted lithographic devices [21, 22]. Recently, we have extended the fabrication of mesoporous materials (carbon, silica, metal oxides) to the R2R 
process [23]. This processing involves (1) a polyethylene terephthalate (PET) substrate for the support, (2) doctor blade casting station to generate a thick film, (3) a temperaturecontrolled evaporation zone to remove residual solvent, and (4) a heated zone to crosslink the precursors. The crosslinked film is easily peeled from the PET substrate to provide a free standing film for calcination / carbonization to yield the mesoporous material. However, it is unclear how the synthetic details and process conditions impact the pore architecture (surface area, pore size and porosity) in this scalable R2R process.

Herein, we demonstrate how the casting solution concentration, TEOS loading and crosslinking temperature impact the pore structures of soft templated, FDU-15-like OMCs fabricated by the $\mathrm{R} 2 \mathrm{R}$ process. For a single template and without using a swelling agent, the pore size of resultant OMCs can be effectively tuned between $3.6 \mathrm{~nm}$ and $5.2 \mathrm{~nm}$. Moreover, very large surface areas, maximum obtained is $2455 \mathrm{~m}^{2} / \mathrm{g}$, are achievable with hundred grams of material produced in a single batch. With the facile synthesis and widely tunable pore properties, these OMCs are evaluated as adsorbents for water purification with methylene green and methyl blue examined as model organic dyes. Intriguingly, the dye capacity is not significantly impacted when the surface area of the OMC is greater than $1500 \mathrm{~m}^{2} / \mathrm{g}$. These studies demonstrate the capability to generate large quantities of high surface area OMCs by R2R processing with pore characteristics easily tunable by synthetic and processing conditions to match application requirements. 


\section{Experimental}

\subsection{Materials}

Phenol (>99\%), formaldehyde (ACS reagent, $37 \mathrm{w} \%$ in $\mathrm{H}_{2} \mathrm{O}$, contains $10-15 \%$ methanol as stabilizer), tetraethyl orthosilicate (TEOS) (>98\%), Pluronic F127, ethanol (>99\%), potassium hydroxide $(\mathrm{KOH},>85 \%)$ and sodium hydroxide $(\mathrm{NaOH},>97 \%)$ were purchased from Sigma-Aldrich and used as received. Thermally-stabilized polyethylene terephthalate (PET) sheet $(125 \mu \mathrm{m})$ was purchased from Terphane Inc. A low-molecular weight phenolic resin was synthesized following the synthetic procedures reported previously for the fabrication of OMCs $[8,24]$.

\subsection{Fabrication of Ordered Mesoporous Carbon (OMC)}

The mesoporous carbons were synthesized following the initial tri-constituent assembly method as reported previously by Zhao and coworkers [25]. Briefly, 4.8 g Pluronic F127 was dissolved in $4 \mathrm{~g}$ of $\mathrm{H}_{2} \mathrm{O}$ and $9-21 \mathrm{~g}$ of ethanol (EtOH). The solution was gently stirred for $2 \mathrm{~h}$ to ensure complete dissolution of the Pluronic F127. $6 \mathrm{~g}$ of resol solution (50 wt \% in ethanol) and 6-9 g of TEOS were added to this solution and heated to $40{ }^{\circ} \mathrm{C}$. Note that this results in an additional $3 \mathrm{~g}$ of ethanol from the resol solution and 4 mols of ethanol from each mol of TEOS after hydrolysis. The additional ethanol from TEOS on hydrolysis is 
significant: $5.31 \mathrm{~g}, 6.63 \mathrm{~g}$, and $7.96 \mathrm{~g}$ of ethanol can be evolved from $6 \mathrm{~g}, 7.5 \mathrm{~g}, 9 \mathrm{~g}$ of TEOS, respectively., After stirring this solution for $2 \mathrm{~h}$ at $40{ }^{\circ} \mathrm{C}$, the solution was cast on the PET substrate by doctor blade coating at $50 \mathrm{~cm} / \mathrm{min}$ as shown in Fig. 1A. The gap of the doctor blade was set to produce a wet film thickness of $400 \mu \mathrm{m}$ (Note: we have found that film thickness does not impact the pore texture for a variety of wet thicknesses examined between $300 \mu \mathrm{m}$ and $500 \mu \mathrm{m}$ ). The residual solvent was removed by heating the film at $50{ }^{\circ} \mathrm{C}$ for $1 \mathrm{~h}$ in the first thermal zone as shown in Fig. $1 \mathrm{~B}$, then a second thermal zone was used to crosslink the phenolic resin at $90,100,120$ or $140{ }^{\circ} \mathrm{C}$ for $3 \mathrm{~h}$. The crosslinked film was peeled from PET substrate and carbonized in a tube furnace (SentroTech Inc.) in $\mathrm{N}_{2}$. The furnace temperature was first increased to $600{ }^{\circ} \mathrm{C}$ at $1{ }^{\circ} \mathrm{C} / \mathrm{min}$, then to $800{ }^{\circ} \mathrm{C}$ at $5{ }^{\circ} \mathrm{C} / \mathrm{min}$ with the temperature held at $800{ }^{\circ} \mathrm{C}$ for $3 \mathrm{~h}$, followed by slow cooling to ambient temperature. The silica within the carbon-silica framework was subsequently etched with $3 \mathrm{M} \mathrm{KOH}$ in ethanol:deionized water (1:1 v:v) solution for 3 days. The powder was washed with deionized water 10 times and then dried under vacuum at $80{ }^{\circ} \mathrm{C}$ for $24 \mathrm{~h}$ prior to characterization. In this work, we use a standard nomenclature for the OMC powders of OMC $-x-y-z$, where $x$ is the mass ratio of TEOS/resol in the casting solution, $y$ is the mass ratio of ethanol/resol excluding the ethanol developed on hydrolysis of TEOS, and $z$ is the crosslinking temperature in ${ }^{\circ} \mathrm{C}$. The solid concentration for the casting solutions is calculated as (solids/(solids+water+ethanol)), where solids consitute the added mass of 
TEOS, F127 and resol. As a control, FDU-15 was fabricated using the previously reported P123:resol ratio and processing conditions $[24,26]$.

\subsection{Characterization}

Transmission small angle X-ray scattering (SAXS) was performed on a Rigaku MicroMax $002+$ instrument with a 2D multiwire area detector and a sealed copper tube operating at $45 \mathrm{kV}$ to produce $\mathrm{CuK}_{\alpha}(\lambda=0.154 \mathrm{~nm}) \mathrm{X}$-rays. The scattering vector $\left(q=4 \pi \lambda^{-1} \sin \theta\right.$, where $\theta$ is the scattering angle) was calibrated using silver behenate, using the primary reflection peak position at $q=1.076 \mathrm{~nm}^{-1}$. The 2D SAXS profiles for the OMC powders were collected in the $q$ range from $0.12 \mathrm{~nm}^{-1}$ to $2 \mathrm{~nm}^{-1}$. The domain spacing of the OMC powders, $d$, was determined from the scattering profiles as $d=2 \pi / q^{*}$, where $q^{*}$ is the primary peak location.

A JEOL-1230 transmission electron microscopy (TEM) with an accelerating voltage of $120 \mathrm{kV}$ was used to image the mesoporous carbon nanostructures using a digital CCD camera. To prepare samples for TEM, the powder was dispersed in acetone at $0.1 \mathrm{mg} / \mathrm{mL}$ and sonicated for $30 \mathrm{~min}$. Two drops from the suspension were placed on $3.05 \mathrm{~mm}$ Cu grid (01753-F, TED PELLA, Inc.) for TEM characterization. To investigate the pore architecture, $\mathrm{N}_{2}$ adsorption and desorption isotherms were obtained using a Micromeritics Tristar. The pore size distributions were calculated from the adsorption isotherms using the Barrett-JoynerHalenda (BJH) model [27]. The surface areas were calculated using the Brunauner-Emmett- 
Teller (BET) methodology [28].

The adsorption of methylene green (MG) and methyl blue (MB) from aqueous solution into the OMCs was determined from UV-Vis spectroscopic measurements of the solution using a variable angle UV-vis spectroscopic ellipsometry (VASE; J.A.Woollam Co., M-2000) in transmission mode. A constant initial dye concentration of $0.5 \mathrm{mg} / \mathrm{mL}$ and constant concentration of the OMC (OMC:water = $1 \mathrm{~g}: 1 \mathrm{~L})$ were used in all experiments. During the adsorption measurements, the suspension containing $\mathrm{OMC}$, dye and water were shaken vigorously using a vortex mixer. The quantity of adsorbed dye $(Q)$ per gram OMC $(\mathrm{g} / \mathrm{g})$ was determined from the spectroscopic measurements with the aid of a calibration curve that related solution adsorption to dye concentration, as $Q=\left(C_{0}-C\right) \times V / W$, where $C$ is the concentration of the dye in the solution after adsorption, $C_{0}$ is the initial concentration of dye in solution, $V$ is the solution volume, and $W$ is the mass of OMC adsorbent.

\section{Results and Discussion}

Ordered mesoporous carbon with high surface area are fabricated via roll-to-roll processing (as illustrated in Fig. 1) employing evaporation-induced self-assembly of a triconstituent polymeric solution (resol, TEOS, Pluronic F127). The governing mechanisms contributing to the formation of the ordered mesostructure are predominately: (i) evaporation of the ethanol to induce cylindrical micelles, (ii) hydrolysis and condensation of 
TEOS to yield silica oligomers that promote ordering of the mesostructure, (iii) crosslinking of resol to stabilize the framework, (iv) carbonization of resol and thermal degradation of Pluronic F127 to yield mesopores and (v) removal of silica by etching to increase the surface area. Here, the impact of fabrication conditions, namely the casting solution concentration, the TEOS content, and crosslinking temperature, on the final structure of the porous carbon are investigated using the processing conditions listed in Table 1.

\subsection{Impact of the solution concentration on structure}

The solution concentration determines the viscosity and therefore the quality of the wet cast film in R2R process. Ideally, the highest initial concentration is desirable to minimize the use of unrecoverable ethanol and to maximize the areal density for the mesoporous material. A fixed TEOS/F127/resol mass ratio (2.5/1.6/1) was used to investigate the impact of solution concentration (Table 1). In this case, the amount of ethanol added to the solution is varied from 5 to 7 to $9 \mathrm{~g}$ per $\mathrm{g}$ resol, which corresponds to ethanol concentration of 45 wt\% (53 wt\%), 53 wt\% (58 wt\%), and 59 wt\% (64 wt\%), respectively, where the number in paranthesis includes the evolved ethanol from complete hydrolysis of TEOS. TEM micrographs (Fig. 2) show no significant differences in the ordered nanostructures of these OMCs. The SAXS patterns (Fig. 2D) of all three samples show three well-defined diffraction peaks with a ratio of $1: \sqrt{ } 3: 2$, consistent with a highly ordered 2-D 
hexagonal cylindrical morphology $(P 6 \mathrm{~mm})$. However, the domain spacing determined from SAXS decreases slightly (10.8 nm to $10.2 \mathrm{~nm}$ to $9.2 \mathrm{~nm}$ ) as the ethanol:resol ratio increases $(5,7$, and 9$)$.

To better probe the impact of ethanol content on the pore structure, $\mathrm{N}_{2}$ adsorptiondesorption isotherms (Fig. 3) are used. The isotherms show typical type-IV curves with a capillary condensation at $\mathrm{p} / \mathrm{p}_{0} \approx 0.5-0.7$ and a $\mathrm{H}_{1}$ hysteresis loop that is characteristic of mesoporous materials with cylindrical channels [14]. As the amount of ethanol added to the casting solution decreases, the surface area increases, up to a maximum of $2455 \mathrm{~m}^{2} / \mathrm{g}$ at an added ethanol:resol (w/w) ratio of 5. Intriguingly, the average pore size from the BJH model increases significantly for the highest surface area material with a much broader pore size distribution (Fig. 3B). The dependence of the pore size on casting solution concentration is consistent with the change in domain spacing determined from SAXS. Prior results have demonstrated a larger extent of shrinkage in thinner films [29, 30], but those films were at the scale of 10's of nm, not microns as the case of the films examined here. In this case, we attribute the larger pore size of OMC-2.5-5-100, compared to OMC-2.5-7-100 and OMC-2.5-9-100, to the limited mobility for the cooperative assembly due to the high solids concentration (45 wt\%), of the initial casting solution when the least amount of ethanol is added $(5 \mathrm{~g} / \mathrm{g}$ resol). This limited mobility will lead to challenges in the selfassembly that kinetically traps the mesostructure. This hypothesized behavior is consistent 
with the broader pore size distribution for OMC-2.5-5-100. This is somewhat unexpected as the more dilute solutions ( 38 and 33 wt \% solids) should progress on evaporation through a similar concentration as the initial concentration (45 wt \% solids) for OMC-2.5-5-100, especially since the large scale synthesis of OMCs (without TEOS) using PU foams [13] yield concentration independent mesostructures. However, solution assembly of block copolymers can be extremely process dependent [31]. We have confirmed that the larger pore size with a broader pore size distribution is reproducible with the surface area for three separate batches leading to surface areas of $2455 \mathrm{~m}^{2} / \mathrm{g}, 2318 \mathrm{~m}^{2} / \mathrm{g}$, and $2372 \mathrm{~m}^{2} / \mathrm{g}$ (see Supplementary material for details). The mesostructure is dependent on the casting solution concentration when the solids content is high (e.g. $45 \mathrm{wt} \%$ solids) for these thick tri-constituent films.

\subsection{Impact of TEOS loading on pore characteristics}

The inclusion of silica in the material provides for mechanical reinforcement of the framework [25, 32] and its removal after carbonization introduces a significant micropore population. The influence of the TEOS:resol $(\mathrm{w} / \mathrm{w})$ ratio $(2,2.5$, and 3$)$ on the final $\mathrm{OMC}$ mesostructure was investigated at a fixed mass ratio of ethanol/F127/resol of 5/1.6/1, which correspond to 18, 22 and 25 wt\% TEOS in solution. Fig. 3 illustrates that there is an optimal TEOS loading for maximizing the ordering of the mesostructure. At lower silica 
content, the ordered structure is well defined (Fig. 4A) similar to the intermediate silica content of OMC-2.5-5-100 (Fig. 1A). The long-range ordering decreases with further increase in TEOS content for OMC-3-5-100 as shown in Fig. 4B with several grains visible in the TEM micrograph. SAXS (Fig. 3C) is used to better quantify the ordering; three clear diffraction peaks are observed for OMC-2.5-5-100, whereas the scattering from OMC-2-5100 exhibits a single sharp peak and that from OMC-3-5-100 exhibits a broad primary peak and a weak second order reflection. These attributes from the scattering indicate that OMC-2.5-5-100 is the best-ordered sample. Moreover, the primary diffraction peak in the SAXS profiles, $q^{*}$, can be quantitatively examined (Fig. $4 \mathrm{C}$ ) to elucidate information on the long-range order. The full width at half maximum (FWHM) of the peak is inversely related to the average grain size [33]. The FWHM is most narrow for OMC-2.5-5-100 (0.09 $\left.\mathrm{nm}^{-1}\right)$ and most broad for OMC-3-5-100 $\left(0.14 \mathrm{~nm}^{-1}\right)$. Additionally, the domain spacing determined from SAXS is significantly smaller for OMC-3-5-100 $(8.6 \mathrm{~nm})$ than either OMC-2.5-5-100 (10.8 nm) or OMC-2-5-100 (10.6 nm).

The $\mathrm{N}_{2}$ adsorption-desorption isotherms provide additional insight into the structural differences in these materials. These isotherms (Fig. 5A) show typical type-IV curves with either a $\mathrm{H}_{1}$ or $\mathrm{H}_{2}$ hysteresis loop, but the size of the hysteresis loop is significantly reduced for OMC-3-5-100 with the capillary condensation occurring at significantly lower partial pressure than the other two OMCs. This is consistent with the partial collapse of the 
mesostructure leading to smaller pores as is best illustrated by the pore size distribution in Fig. 5B. In this case, the collapse likely occurs after removal of the silica from the framework. The carbon content is significantly smaller, which appears to be insufficient to support the structure against capillary forces associated with the evaporation of ethanol/water from the etching process. This collapse leads to an average pore size for OMC-3-5-100 that is $30 \%$ smaller than the other two OMCs and a much smaller pore volume (Table 1). Moreover, the surface area of OMC-3-5-100 (1269 m²/g) is much less than for OMC-2.5-5-100 (2455 m²/g) or OMC-2-5-100 (1508 $\left.\mathrm{m}^{2} / \mathrm{g}\right)$. As the silica was the majority phase in the wall, the micropores in the wall framework likely are also partially collapsed contributing to the decreased surface area.

\subsection{Role of crosslinking temperature on porous structure}

With tri-constituent self assembly, the condensation of silica oligomers drives self assembly during solvent evaporation [32], unlike the limited ordering that arises for resolPluronic alone [34-36]. Despite the initial development of the mesostructure on solvent evaporation, the crosslinking temperature impacts the ultimate ordered structure of the OMCs. For temperatures between $90-140^{\circ} \mathrm{C}$, a well defined ordered structure is clearly observed in the TEM micrographs in all cases for the OMCs (Fig. 6), although defects in the ordered structure are clearly evident for the $\mathrm{OMC}$ crosslinked at $140{ }^{\circ} \mathrm{C}$ (Fig. 6C). This 
suggests that the mesostructure evolves during crosslinking as the resol will be more crosslinked at higher temperatures [37]. SAXS measurements provide a route to better understand these differences as shown in Fig. 6D. A primary diffraction peak is observed for all of the samples, but the primary peak position $\left(q^{*}\right)$ and the breadth of this peak are both strongly dependent on the crosslinking temperature. For OMC-2.5-5-90, a complex broad scattering peak is present in the SAXS profile; there appears to be two distinct mesostructure spacings from this scattering pattern. Increasing the crosslinking temperature to $100^{\circ} \mathrm{C}$, the primary diffraction peak narrows and shifts to lower $\mathrm{q}(q=0.58$ $\left.\mathrm{nm}^{-1}\right)$; additionally, the SAXS profile contains two higher order diffraction peaks, which illustrates the highly ordered structure that is obtained at this crosslinking temperature. Further increasing the crosslinking temperature to $120^{\circ} \mathrm{C}$ decreases the domain spacing from $10.8 \mathrm{~nm}$ to $9.7 \mathrm{~nm}$ and also decreases the ordering of the mesostructure as evidenced by the broadening of the primary diffraction peak position and loss of higher order reflections.

The crosslinking temperature also impacts the pore texture as determined from $\mathrm{N}_{2}$ adsorption-desorption isotherms shown in Fig. 7A. The hysteresis loop in these isotherms is a pronounced $\mathrm{H}_{2}$-type loop at the extremes of the temperatures examined and approaches an $\mathrm{H}_{1}$-type hysteresis loop for OMC-2.5-5-100 (intermediate temperature). The hysteresis loop of $\mathrm{H}_{1}$-type is a characteristic of capillary condensation and evaporation of well-defined 
cylindrical pores that are open at both ends, while $\mathrm{H}_{2}$-type hysteresis loops are generally found in more disordered materials. This observation is consistent with the SAXS results, where the OMC-2,5-5-100 shows the best ordered mesostructure. The largest surface area and pore volume are obtained for OMC-2.5-5-100. Additionally from these adsorptiondesorption isotherms, the collapse (or failure to order) of the pores for OMC-2.5-5-140 is suggested by the much lower pore volume $\left(0.75 \mathrm{~cm}^{3} / \mathrm{g}\right)$ and surface area $\left(1093 \mathrm{~m}^{2} / \mathrm{g}\right)$ than that found at lower crosslinking temperatures $\left(>1.5 \mathrm{~cm}^{3} / \mathrm{g}\right.$ and $\left.>1800 \mathrm{~m}^{2} / \mathrm{g}\right)$. This is consistent with the very weak diffraction peak from SAXS for OMC-2.5-5-140. As shown in Fig. 7B, a single narrow distribution for pore size is found for all four OMCs. The average pore size for all of the OMCs is $3.7 \pm 0.1 \mathrm{~nm}$ except for OMC-2.5-5-100 where a much larger pore size $(5.2 \mathrm{~nm})$ is obtained.

To explain these differences, the prior literature on the fabrication of OMCs without TEOS provides some clues. For these materials, the crosslinking temperature controls the relative rate of ordering and crosslinking [38]. At lower temperatures, the crosslinking reaction is sufficiently slow and does not impact ordering, but the crosslinking extent is lower and does not fully stabilize the mesostructure through carbonization [37]. At high temperatures, the resol crosslinks too fast for a well ordered mesostructure to develop. For OMC powders fabricated with Pluronic and resol, $120{ }^{\circ} \mathrm{C}$ has been reported as the optimal crosslinking temperature [38]. However, the silica in the framework will assist in stabilizing 
the structure [32], so a lower temperature may improve the ordering similar to a prior report using a two stage crosslinking process where initially $100{ }^{\circ} \mathrm{C}$ is used to promote the ordering, followed by a much higher temperature $\left(150{ }^{\circ} \mathrm{C}\right)$ to crosslink the resol [37]. This competition between ordering and crosslinking likely provides the origins of the bestordered structure for OMC-2.5-5-100. The extent of ordering impacts the mechanical properties [39], which in turn are critical to the extent of contraction of the pores during calcination. [40] These effects likely are responsible for the smaller domain spacing for OMC-2.5-5-140. Despite the large silica content, the crosslinking temperature for the resol is an important factor in determining the final structure of these OMCs.

Fig 8 schematically summarizes the influence of the three parameters examined here: Solution concentration, TEOS concentration and temperature for thermopolymerization. Increasing the concentration of added ethanol in the casting solution leads to (1) decreased average pore size, (2) decreased surface area, and (3) slightly narrowed pore size distribution. For the TEOS concentration dependence, there is an optimal concentration (22 wt \%) to maximize the (1) extent of ordering, (2) surface area, and (3) d-spacing of the mesoporous carbon. Similarly, an intermediate crosslinking temperature of $100{ }^{\circ} \mathrm{C}$ leads to the best-ordered mesostructure and a larger pore size.

\subsection{Dye adsorption capacity of synthesized OMCs}


To demonstrate their potential use in water purification, the fabricated OMCs with various surface area and pore structure were contacted with an aqueous solution of different dyes (methylene green and methyl blue). The equilibrium dye absorbed $(Q)$ for the various OMC samples at $25^{\circ} \mathrm{C}$ are shown in Fig. $9 \mathrm{~A}$. FDU-15 with $500 \mathrm{~m}^{2} / \mathrm{g}$ surface area is provided as a control for comparison [24]. For methylene green (MG), as the surface area of the OPC increases from $500 \mathrm{~m}^{2} / \mathrm{g}$ to $1269,1508,2058$ and $2455 \mathrm{~m}^{2} / \mathrm{g}$, Q increases from 0.3 $\mathrm{g} / \mathrm{g}$ to $0.34,0.41,0.43$ and $0.436 \mathrm{~g} / \mathrm{g}$. This is consistent with previous reports where the adsorpition capacity of MG scales with the surface area [41]. The limited increase in capacity of MG at the higher surface area suggests that the increased surface area in this case is not readily accessible to MG. The maxmium adsorption capacity of MG $(0.436 \mathrm{~g} / \mathrm{g})$ iis obtained with OMC-2.5-5-100, which is significantly higher than previous report of MCM$41(0.1 \mathrm{~g} / \mathrm{g})[42]$. For methyl blue (MB), the highest adsorption capacity is obtained using OMC-2.5-7-100 $(0.378 \mathrm{~g} / \mathrm{g})$, which is greater than $\mathrm{KOH}$-activated carbon $(0.3 \mathrm{~g} / \mathrm{g})$ and similar to steam activated carbon $(0.38 \mathrm{~g} / \mathrm{g})$ [43]. Interestingly, when the surface area increases from $2058 \mathrm{~m}^{2} / \mathrm{g}$ to $2455 \mathrm{~m}^{2} / \mathrm{g}$, the average MB capacity for the OMC slightly decreases from $0.378 \mathrm{~g} / \mathrm{g}$ (surface area: $2058 \mathrm{~m}^{2} / \mathrm{g}$ ) to $0.372 \mathrm{~g} / \mathrm{g}$, but this is not outside of the uncertainty of the measurement. There is a significant standard deviation in the MB capacity for OMC-2.5-5-100, which suggests that the heterogeneity in this material (as evidenced by the broadened diffraction peaks from SAXS) impacts the dye capacity, likely 
through the distribution of micropores.

In addition to the capacity, the adsorption kinetics are also important to consider for the utility of these OMCs for water purification. Fig. 9B shows the fractional dye removal of both MG and MB as a function of contact time for OMC-2.5-5-100. After $5 \mathrm{~min}$, the OMC adsorbs 60 and $44 \%$ of its equilibrium capacity for $M G$ and $M B$, respectively. The rate of approach to equilibrium decreases for higher percentages of adsorption capacity with approximately 60 and 100 min required for the OMC to reach its adsorption capacity for $M G$ and $M B$, respectively. To more quantitatively describe the adsorption kinetics of the dyes ( $M G$ and $M B$ ), a pseudo-second-order model was used to determine an effective adsorption rate, $k$ :

$$
\frac{t}{Q_{t}}=\frac{1}{k Q^{2}}+\frac{1}{Q} t
$$

where $Q_{t}$ and $Q$ are the specific mass of dye adsorbed at time $t$ and equilibrium. As shown in the inset of Fig. 9B, $t / Q_{t}$ increases linearly with time and thus the pseudo-second-order model can describe the adsorption kinetics. The effective rate constant for $M G$ is 0.828 (min.g dye/g OMC) $)^{-1}$, which is approximately a factor of 2 greater than for $\mathrm{MB}(0.415 \mathrm{~min} \cdot \mathrm{g}$ dye/g $O M C)^{-1}$ ). This is consistent with the qualitative result that the equilibration takes much longer for $\mathrm{MB}(\sim 100 \mathrm{~min})$ than for $\mathrm{MG}$ ( $60 \mathrm{~min})$. Since the adsorbate is identical in this case, the difference in the rate constants is primarily due to the difference in the molecular sizes of $M G$ and $M B$. The largest dimension of $M B$ molecule $(\approx 2.5 \mathrm{~nm})$ is almost 
1.6 times greater than that of $M G(\approx 1.4 \mathrm{~nm})[44]$. Thus, the small pores from the removal of silica are less effective for promoting sites for adsorption of the larger dye.

\section{Conclusions}

The large scale synthesis of uniform mesoporous carbon with varying pore characteristics is demonstrated using process control during R2R fabrication. Tri-consituent cooperative assembly provides mesopores templated by Pluronic F127 and large micropores from etching silica from the framework. Both evaporation and thermallyinduced self assembly are shown be at play and influence the resulting pore chacteristics of the OMCs. Framework shrinkage can be supressed by increasing solid concentration in the casting solution and the fraction of TEOS in the formulation. However, the pore structure appears to collapse partially after etching of the silica for very high TEOS concentrations. An optimal crosslinking temperature range exists on the basis of insufficient crosslinking at low temperature and insufficient time to re-organize the self-assembled structure at higher temperatures. Through changes in crosslinking temperature, the pore size and the surface area are effectively controlled from $0.75 \mathrm{~nm}$ and $1090 \mathrm{~m}^{2} / \mathrm{g}$ at $140{ }^{\circ} \mathrm{C}$ to $2.22 \mathrm{~nm}$ and 2450

$\mathrm{m}^{2} / \mathrm{g}$ at $100{ }^{\circ} \mathrm{C}$. The applicability of these OMCs to dye removal from aqueous solution is demonstrated with adsorption capacities of $0.436 \mathrm{~g} \mathrm{MG} / \mathrm{g}$ and $0.378 \mathrm{~g} \mathrm{MB} / \mathrm{g}$. This 
difference in adsoprtion capacities of OMCs for MG and MB appears to be determined by the molecular size of the dye. R2R processing combined with processing sensitivity provides a facile route to tune the properties of mesoporous materials, fabricated in sufficient quantity to enable through investigations of these materials in a variety of applications.

\section{Acknowledgements}

This work is partially supported by the National Science Foundation (NSF) under grant no. CBET-1159295. The authors thank Clinton Wiener and Cannon Morgan for their assistance with the dye adsorption measurements.

\section{Refereneces}

[1] R. Ryoo, S.H. Joo, M. Kruk, M. Jaroniec, Ordered mesoporous carbons, Adv. Mater., 13 (2001) 677-681.

[2] C. Liang, Z. Li, S. Dai, Mesoporous carbon materials: Synthesis and modification, Angew. Chem. Int. Ed., 47 (2008) 3696-3717.

[3] M. Endo, C. Kim, K. Nishimura, T. Fujino, K. Miyashita, Recent development of carbon materials for Li ion batteries, Carbon, 38 (2000) 183-197.

[4] H.-J. Liu, X.-M. Wang, W.-J. Cui, Y.-Q. Dou, D.-Y. Zhao, Y.-Y. Xia, Highly ordered mesoporous carbon nanofiber arrays from a crab shell biological template and its application in supercapacitors and fuel cells, J. Mater. Chem., 20 (2010) 4223-4230.

[5] A.F. Ismail, L.I.B. David, A review on the latest development of carbon membranes for gas separation, J. Membr. Sci., 193 (2001) 1-18.

[6] X. Zhuang, Y. Wan, C. Feng, Y. Shen, D. Zhao, Highly Efficient Adsorption of Bulky Dye Molecules in Wastewater on Ordered Mesoporous Carbons, Chem. Mater., 21 (2009) 706716.

[7] T. Peng, W. Sun, X. Sun, N. Huang, Y. Liu, C. Bu, S. Guo, X.-Z. Zhao, Direct tri-constituent co-assembly of highly ordered mesoporous carbon counter electrode for dye-sensitized 
solar cells, Nanoscale, 5 (2013) 337-341.

[8] Y. Meng, D. Gu, F.Q. Zhang, Y.F. Shi, H.F. Yang, Z. Li, C.Z. Yu, B. Tu, D.Y. Zhao, Ordered mesoporous polymers and homologous carbon frameworks: Amphiphilic surfactant templating and direct transformation, Angew. Chem. Int. Ed., 44 (2005) 7053-7059.

[9] C.D. Liang, S. Dai, Synthesis of mesoporous carbon materials via enhanced hydrogenbonding interaction, J. Am. Chem. Soc., 128 (2006) 5316-5317.

[10] X. Sun, Y. Shi, P. Zhang, C. Zheng, X. Zheng, F. Zhang, Y. Zhang, N. Guan, D. Zhao, G.D. Stucky, Container Effect in Nanocasting Synthesis of Mesoporous Metal Oxides, J. Am. Chem. Soc., 133 (2011) 14542-14545.

[11] Z. Tian, M.A. Snyder, Hard Templating of Symmetric and Asymmetric Carbon Thin Films with Three-Dimensionally Ordered Mesoporosity, Langmuir, 30 (2014) 9828-9837.

[12] B.E. Wilson, S.G. Rudisill, A. Stein, Use of a sacrificial layer for an efficient EISA synthesis of mesoporous carbon, Microporous Mesoporous Mater., 197 (2014) 174-179.

[13] J. Wang, C. Xue, Y. Lv, F. Zhang, B. Tu, D. Zhao, Kilogram-scale synthesis of ordered mesoporous carbons and their electrochemical performance, Carbon, 49 (2011) 45804588.

[14] R.L. Liu, Y.F. Shi, Y. Wan, Y. Meng, F.Q. Zhang, D. Gu, Z.X. Chen, B. Tu, D.Y. Zhao, Triconstituent Co-assembly to ordered mesostructured polymer-silica and carbon-silica nanocomposites and large-pore mesoporous carbons with high surface areas, J. Am. Chem. Soc., 128 (2006) 11652-11662.

[15] D. Feng, Y.Y. Lv, Z.X. Wu, Y.Q. Dou, L. Han, Z.K. Sun, Y.Y. Xia, G.F. Zheng, D.Y. Zhao, FreeStanding Mesoporous Carbon Thin Films with Highly Ordered Pore Architectures for Nanodevices, J. Am. Chem. Soc., 133 (2011) 15148-15156.

[16] W. Yang, T.-P. Fellinger, M. Antonietti, Efficient Metal-Free Oxygen Reduction in Alkaline Medium on High-Surface-Area Mesoporous Nitrogen-Doped Carbons Made from Ionic Liquids and Nucleobases, J. Am. Chem. Soc., 133 (2011) 206-209.

[17] J. Schuster, G. He, B. Mandlmeier, T. Yim, K.T. Lee, T. Bein, L.F. Nazar, Spherical Ordered Mesoporous Carbon Nanoparticles with High Porosity for Lithium-Sulfur Batteries, Angew. Chem. Int. Ed., 51 (2012) 3591-3595.

[18] X. Hu, L. Chen, Y. Zhang, Q. Hu, J. Yang, Y. Chen, Large-Scale Flexible and Highly Conductive Carbon Transparent Electrodes via Roll-to-Roll Process and Its High Performance Lab-Scale Indium Tin Oxide-Free Polymer Solar Cells, Chem. Mater., 26 (2014) 6293-6302.

[19] H. Kang, H. Park, Y. Park, M. Jung, B.C. Kim, G. Wallace, G. Cho, Fully Roll-to-Roll Gravure Printable Wireless (13.56 MHz) Sensor-Signage Tags for Smart Packaging, Sci. Rep., 4 (2014) 5387 (1-7).

[20] R.R. Søndergaard, M. Hösel, F.C. Krebs, Roll-to-Roll fabrication of large area functional organic materials, J. Poly. Sci. B: Poly. Phys., 51 (2013) 16-34. 
[21] S.H. Ahn, L.J. Guo, Large-Area Roll-to-Roll and Roll-to-Plate Nanoimprint Lithography: A Step toward High-Throughput Application of Continuous Nanoimprinting, ACS Nano, 3 (2009) 2304-2310.

[22] S.H. Ahn, L.J. Guo, High-speed roll-to-roll nanoimprint lithography on flexible plastic substrates, Adv. Mater., 20 (2008) 2044-2049.

[23] Z. Qiang, Y.H. Guo, H. Liu, S.Z.D. Cheng, M. Cakmak, K.A. Cavicchi, B.D. Vogt, Large-

Scale Roll-to-Roll Fabrication of Ordered Mesoporous Materials using Resol-Assisted Cooperative Assembly, ACS Appl. Mater. Inter., 7 (2015) 4306-4310.

[24] Y. Meng, D. Gu, F.Q. Zhang, Y.F. Shi, L. Cheng, D. Feng, Z.X. Wu, Z.X. Chen, Y. Wan, A. Stein, D.Y. Zhao, A family of highly ordered mesoporous polymer resin and carbon structures from organic-organic self-assembly, Chem. Mater., 18 (2006) 4447-4464.

[25] R. Liu, Y. Shi, Y. Wan, Y. Meng, F. Zhang, D. Gu, Z. Chen, B. Tu, D. Zhao, Triconstituent Co-assembly to ordered mesostructured polymer-silica and carbon-silica nanocomposites and large-pore mesoporous carbons with high surface areas, J. Am. Chem. Soc., 128 (2006) $11652-11662$.

[26] J. Xue, G. Singh, Z. Qiang, A. Karim, B.D. Vogt, Unidirectional self-assembly of soft templated mesoporous carbons by zone annealing, Nanoscale, 5 (2013) 7928-7935.

[27] E.P. Barrett, L.G. Joyner, P.P. Halenda, The determination of pore volume and area distributions in porous substances. 1. Computations from nitrogen isotherms, J. Am. Chem. Soc., 73 (1951) 373-380.

[28] S. Brunauer, P.H. Emmett, E. Teller, Adsorption of Gases in Multimolecular Layers, J. Am. Chem. Soc., 60 (1938) 309-318.

[29] Y. Wei, D.L. Jin, C.C. Yang, G. Wei, A fast convenient method to prepare hybrid sol-gel materials with low volume-shrinkages, J. Sol-Gel Sci. Technol., 7 (1996) 191-201.

[30] B.D. Vogt, V.L. Chavez, M. Dai, M.R.C. Arreola, L. Song, D. Feng, D. Zhao, G.M. Perera, G.E. Stein, Impact of Film Thickness on the Morphology of Mesoporous Carbon Films Using Organic-Organic Self-Assembly, Langmuir, 27 (2011) 5607-5615.

[31] R.C. Hayward, D.J. Pochan, Tailored Assemblies of Block Copolymers in Solution: It Is All about the Process, Macromolecules, 43 (2010) 3577-3584.

[32] L.Y. Song, D. Feng, H.J. Lee, C.Q. Wang, Q.Y. Wu, D.Y. Zhao, B.D. Vogt, Stabilizing Surfactant Templated Cylindrical Mesopores in Polymer and Carbon Films through Composite Formation with Silica Reinforcement, J. Phys. Chem. C, 114 (2010) 9618-9626.

[33] B.D. Vogt, H.J. Lee, W.L. Wu, Y.F. Liu, Specular X-ray reflectivity and small angle neutron scattering for structure determination of ordered mesoporous dielectric films, J. Phys. Chem. B, 109 (2005) 18445-18450.

[34] M. Florent, C. Xue, D. Zhao, D. Goldfarb, Formation Mechanism of Cubic Mesoporous Carbon Monolith Synthesized by Evaporation-Induced Self-assembly, Chem. Mater., 24 (2012) 383-392. 
[35] J. Schuster, R. Koehn, M. Doeblinger, A. Keilbach, H. Amenitsch, T. Bein, In Situ SAXS Study on a New Mechanism for Mesostructure Formation of Ordered Mesoporous Carbons: Thermally Induced Self-Assembly, J. Am. Chem. Soc., 134 (2012) 11136-11145. [36] J. Xue, G. Singh, Z. Qiang, K.G. Yager, A. Karim, B.D. Vogt, Facile control of long range orientation in mesoporous carbon films with thermal zone annealing velocity, Nanoscale, 5 (2013) 12440-12447.

[37] Y.Z. Zhang, Z. Qiang, B.D. Vogt, Relationship between crosslinking and ordering kinetics for the fabrication of soft templated (FDU-16) mesoporous carbon thin films, RSC Adv., 4 (2014) 44858-44867.

[38] Y. Meng, D. Gu, F. Zhang, Y. Shi, L. Cheng, D. Feng, Z. Wu, Z. Chen, Y. Wan, A. Stein, D. Zhao, A family of highly ordered mesoporous polymer resin and carbon structures from organic-organic self-assembly, Chem. Mater., 18 (2006) 4447-4464.

[39] H. Fan, C. Hartshorn, T. Buchheit, D. Tallant, R. Assink, R. Simpson, D.J. Kisse, D.J. Lacks, S. Torquato, C.J. Brinker, Modulus-density scaling behaviour and framework architecture of nanoporous self-assembled silicas, Nat. Mater., 6 (2007) 418-423.

[40] L. Song, D. Feng, H.-J. Lee, C. Wang, Q. Wu, D. Zhao, B.D. Vogt, Stabilizing Surfactant Templated Cylindrical Mesopores in Polymer and Carbon Films through Composite Formation with Silica Reinforcement, J. Phys. Chem. C, 114 (2010) 9618-9626.

[41] M. Dai, B.D. Vogt, High capacity magnetic mesoporous carbon-cobalt composite adsorbents for removal of methylene green from aqueous solutions, J. Colloid Interface Sci., 387 (2012) 127-134.

[42] C.-K. Lee, S.-S. Liu, L.-C. Juang, C.-C. Wang, K.-S. Lin, M.-D. Lyu, Application of MCM-41 for dyes removal from wastewater, J. Hazard. Mater., 147 (2007) 997-1005.

[43] F.C. Wu, R.L. Tseng, C.C. Hu, Comparisons of pore properties and adsorption performance of $\mathrm{KOH}$-activated and steam-activated carbons, Microporous Mesoporous Mater., 80 (2005) 95-106.

[44] L. Meng, X. Zhang, Y. Tang, K. Su, J. Kong, Hierarchically porous silicon-carbon-nitrogen hybrid materials towards highly efficient and selective adsorption of organic dyes, Sci. Rep., 5 (2015) 7910 (1-16). 
Table 1 Fabrication conditions for OMCs and their corresponding structural properties

\begin{tabular}{lccccccc}
\hline Sample name & $\begin{array}{c}\text { TEOS:resol } \\
(\mathrm{w}: \mathrm{w})\end{array}$ & $\begin{array}{c}\text { EtOH:resol } \\
\mathrm{w}: \mathrm{w}\end{array}$ & $\begin{array}{c}\text { Crosslink } \\
\text { temp. } \\
\left({ }^{\circ} \mathrm{C}\right)\end{array}$ & $\begin{array}{c}\text { Domain } \\
\text { spacing } \\
(\mathrm{nm})\end{array}$ & $\begin{array}{c}\text { Surface } \\
\text { area } \\
\left(\mathrm{m}^{2} / \mathrm{g}\right)\end{array}$ & $\begin{array}{c}\text { Pore } \\
\text { volume } \\
\left(\mathrm{cm}^{3} / \mathrm{g}\right)\end{array}$ & $\begin{array}{c}\text { Pore size } \\
\text { diameter } \\
(\mathrm{nm})\end{array}$ \\
\hline OMC-2.5-9-100 & 2.5 & 9 & 100 & 9.2 & 1823 & 1.41 & 3.7 \\
OMC-2.5-7-100 & 2.5 & 7 & 100 & 10.2 & 2058 & 1.49 & 3.6 \\
OMC-2.5-5-100 & 2.5 & 5 & 100 & 10.8 & 2455 & 2.22 & 5.2 \\
OMC-3-5-100 & 3 & 5 & 100 & 8.6 & 1269 & 0.81 & 3.4 \\
OMC-2-5-100 & 2 & 5 & 100 & 10.6 & 1508 & 2.28 & 5.1 \\
OMC-2.5-5-90 & 2.5 & 5 & 90 & 9.9 & 1808 & 1.51 & 3.8 \\
OMC-2.5-5-120 & 2.5 & 5 & 120 & 9.7 & 1862 & 1.62 & 3.8 \\
OMC-2.5-5-140 & 2.5 & 5 & 140 & 8.8 & 1093 & 0.75 & 3.6 \\
\hline
\end{tabular}

${ }^{a}$ This only includes all of the ethanol added to the casting solution. Ethanol generated by

hydrolysis of TEOS is neglected in this ratio 


\section{Figure Captions}

Fig. 1 Images of components of the R2R tool used for the fabrication of the OMCs. (A) The tri-constituent solution is first cast using a doctor blade. (B) Convection heating zones are used for solvent evaporation and crosslinking of the resol.

Fig. 2 TEM images of OMCs fabricated with ethanol:resol ratio of $(A) 5$, (B) 7 , and (C) 9 with fixed TEOS/F127/resol mass ratio (2.5/1.6/1). (D) SAXS patterns of these materials illustrate the highly ordered hexagonally packed mesostructure.

Fig. 3 (A) $\mathrm{N}_{2}$ adsorption-desorption isotherms of OMCs fabricated using casting solutions with different ethanol concentration and (B) their corresponding pore size distributions. The isotherms are vertically offset by 200 and $400 \mathrm{~cm}^{3} / \mathrm{g}$ for OMC-2.5-7-100 and OMC-2.5-9100 , respectively.

Fig. 4 TEM micrographs of OMCs fabricated with TEOS:resol ratios of (A) 2 and (B) 3 with fixed mass ratio of ethanol/F127/resol of 5/1.6/1. (C) SAXS profiles of corresponding samples and an intermediate TEOS content.

Fig. 5 (A) $\mathrm{N}_{2}$ adsorption-desorption isotherms of OMCs fabricated with different TEOS:resol ratios and $(B)$ their corresponding pore size distribution. The isotherms are vertically offset 
by 200 and $1500 \mathrm{~cm}^{3} / \mathrm{g}$ for OMC-2-5-100 and OMC-3-5-100, respectively.

Fig. 6 TEM micrographs of OMCs fabricated using crosslinking temperature of $(A) 90^{\circ} \mathrm{C}$, (B) $120^{\circ} \mathrm{C}$ and (C) $140{ }^{\circ} \mathrm{C}$. (D) SAXS patterns of the corresponding samples.

Fig. 7 (A) $\mathrm{N}_{2}$ adsorption-desorption isotherms of OMCs fabricated using different crosslinking temperatures and (B) their corresponding pore size distributions. The isotherms are vertically offset by 300,600 , and $1500 \mathrm{~cm}^{3} / \mathrm{g}$ for OMC-2.5-5-100, OMC-2.5-5-120 and OMC-2.5-5-140, respectively.

Fig. 8 Schematic summarizing the influence of the ethanol concentration, TEOS concentration, and crosslinking temperature on the characteristics of mesoporous carbons fabricated by a roll-to-roll process.

Fig. 9 (A) Dye adsorption capacity as a function of surface areas of mesoporous carbon; (B) Effect of contact time on different dye adsorption for OMC-2.5-5-100. Inset illustrates the pseudo-second-order adsorption kinetics for both MG and MB. 


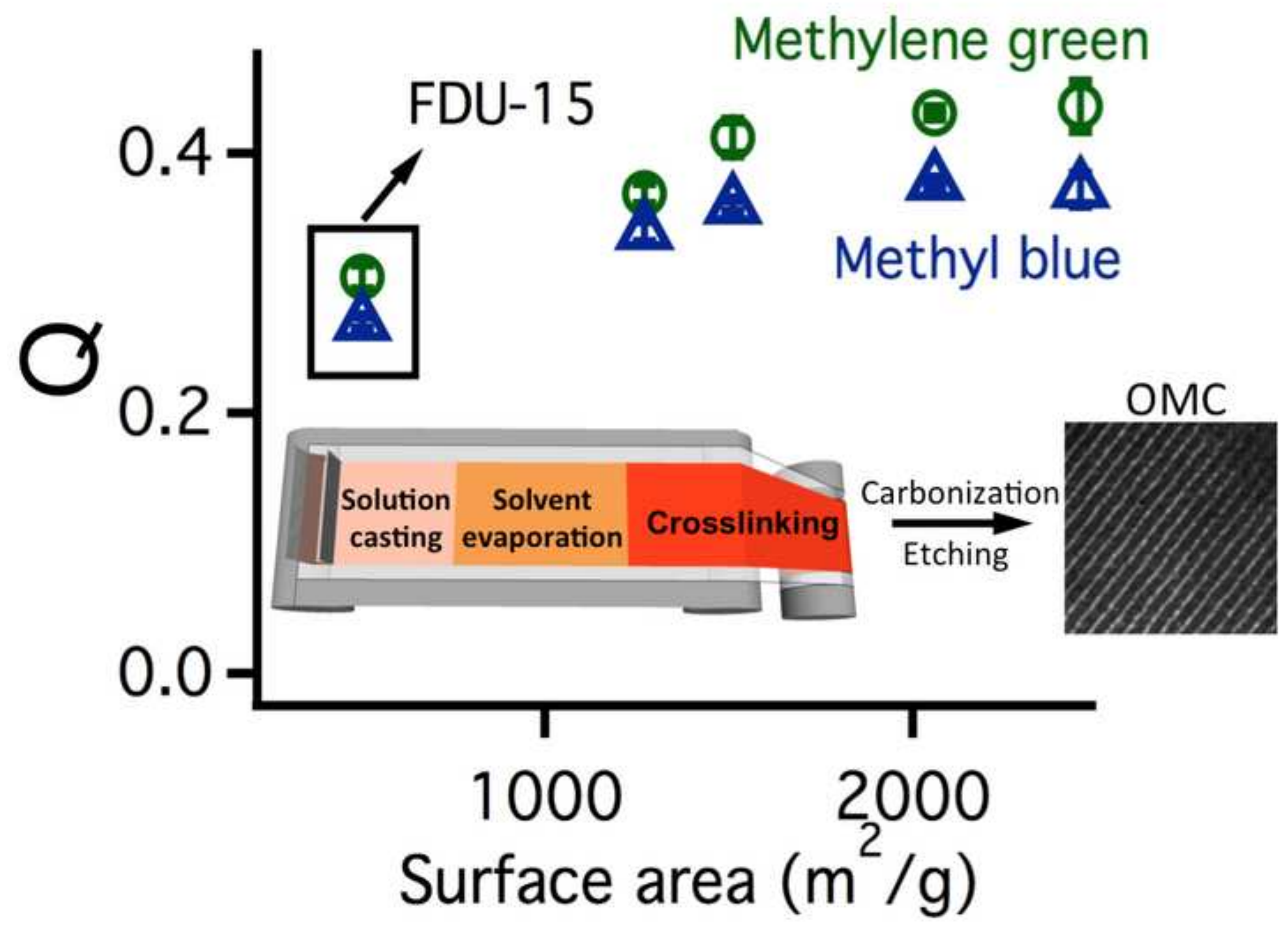




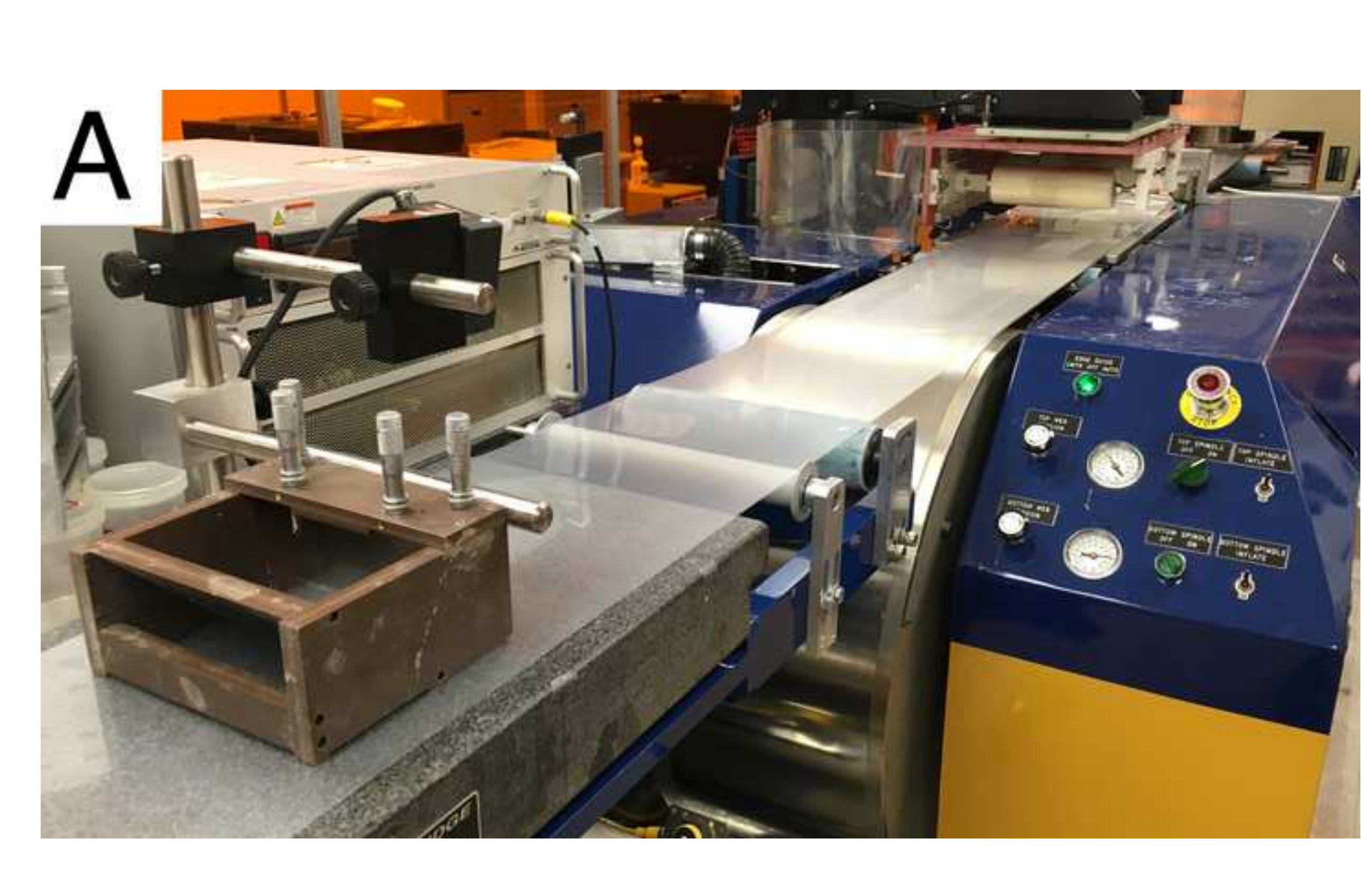

$$
\text { . }
$$

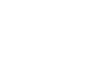$$
\text { ( }
$$
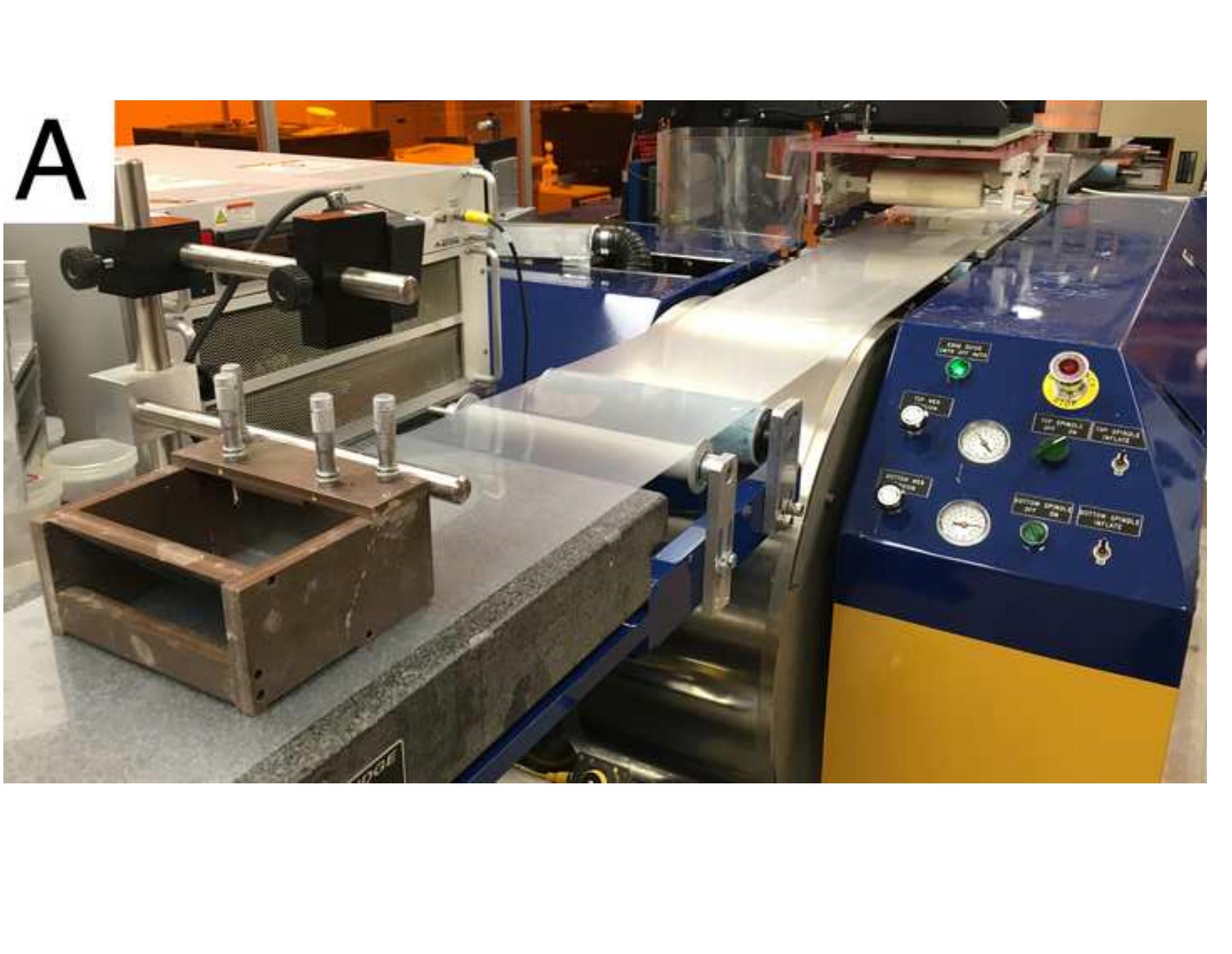

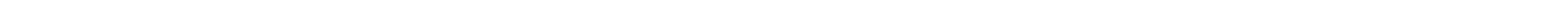


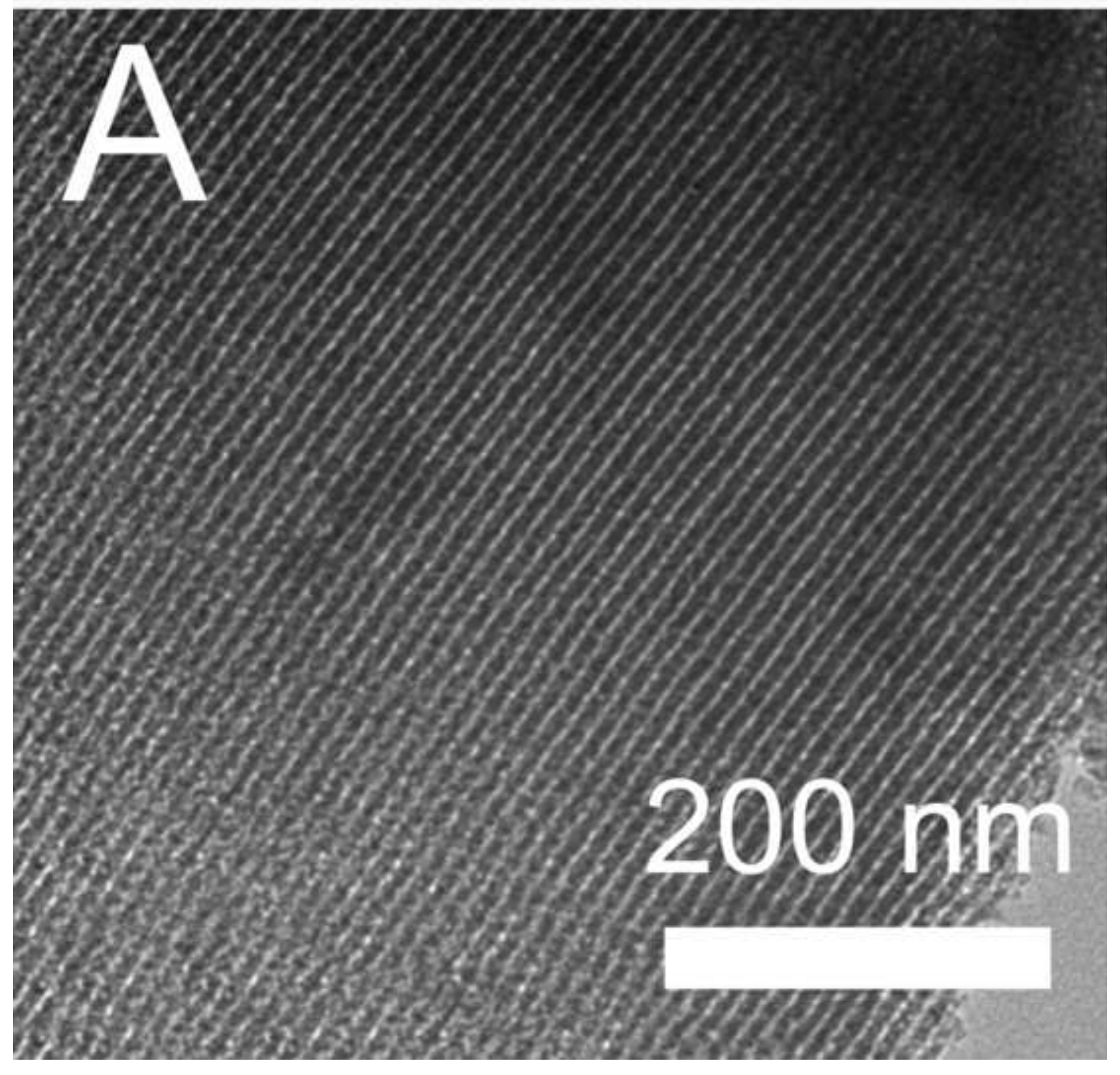

\author{
.
}

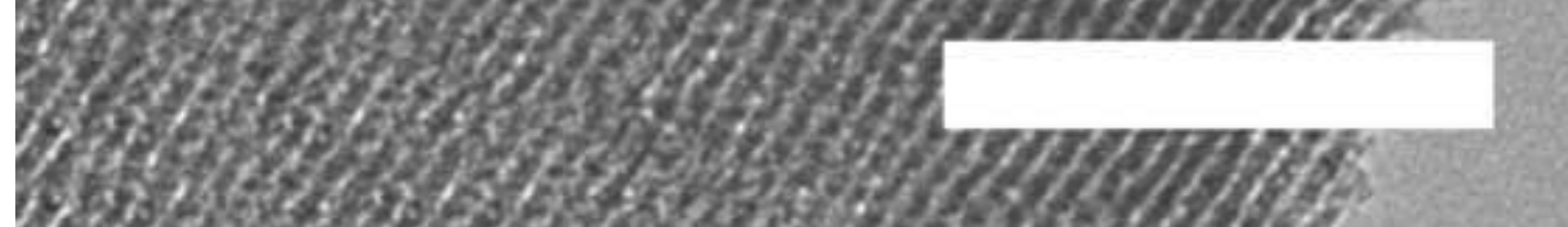
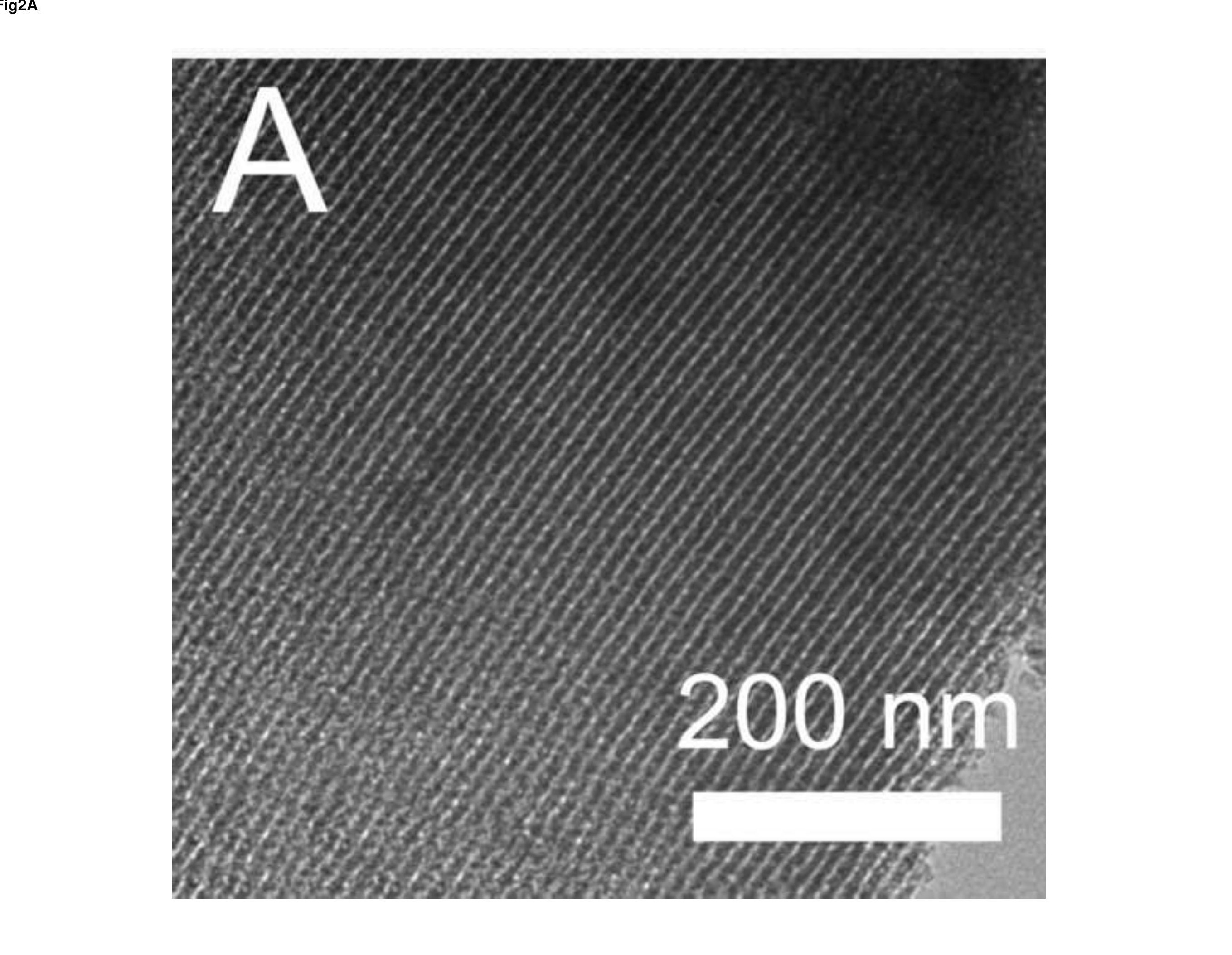

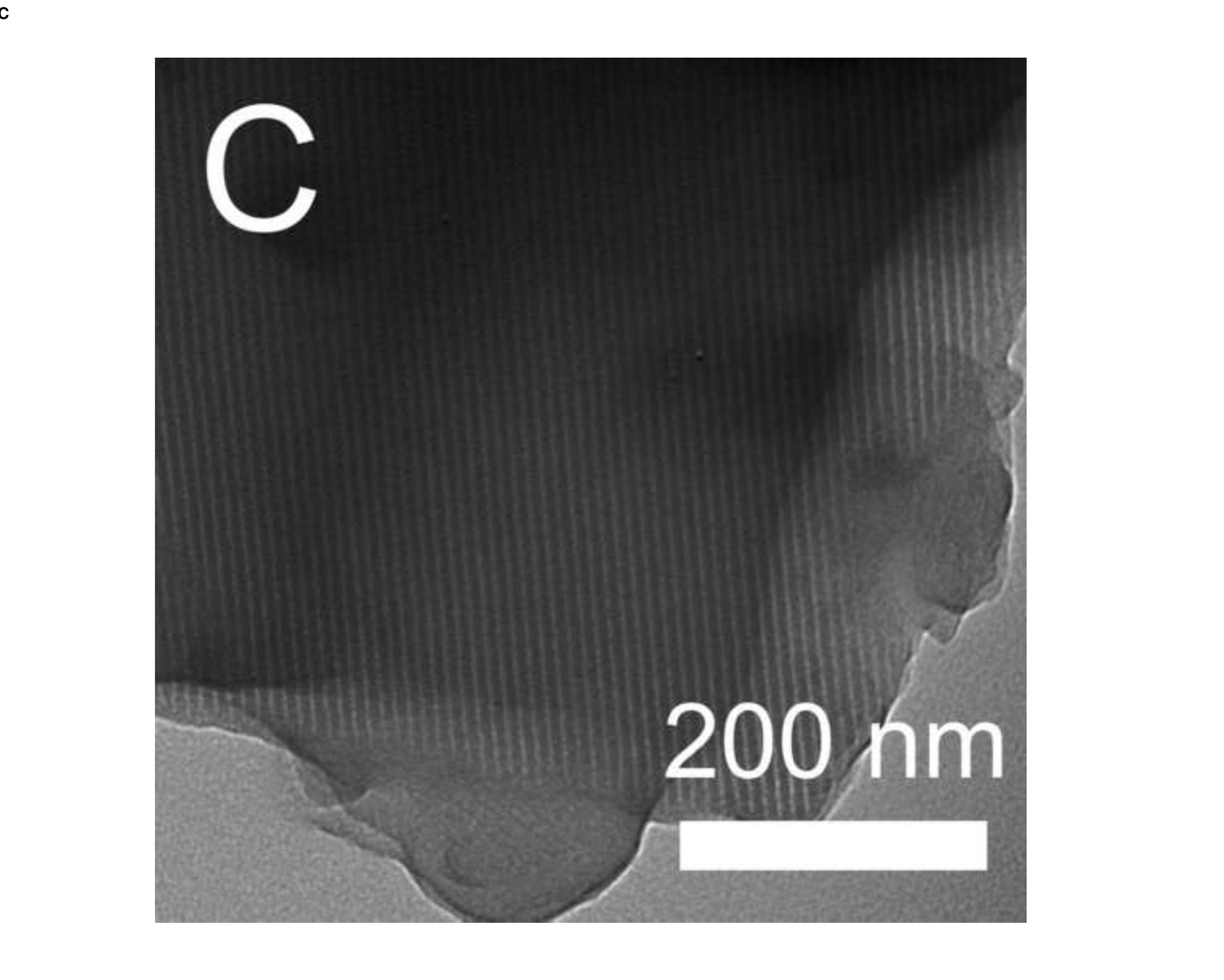


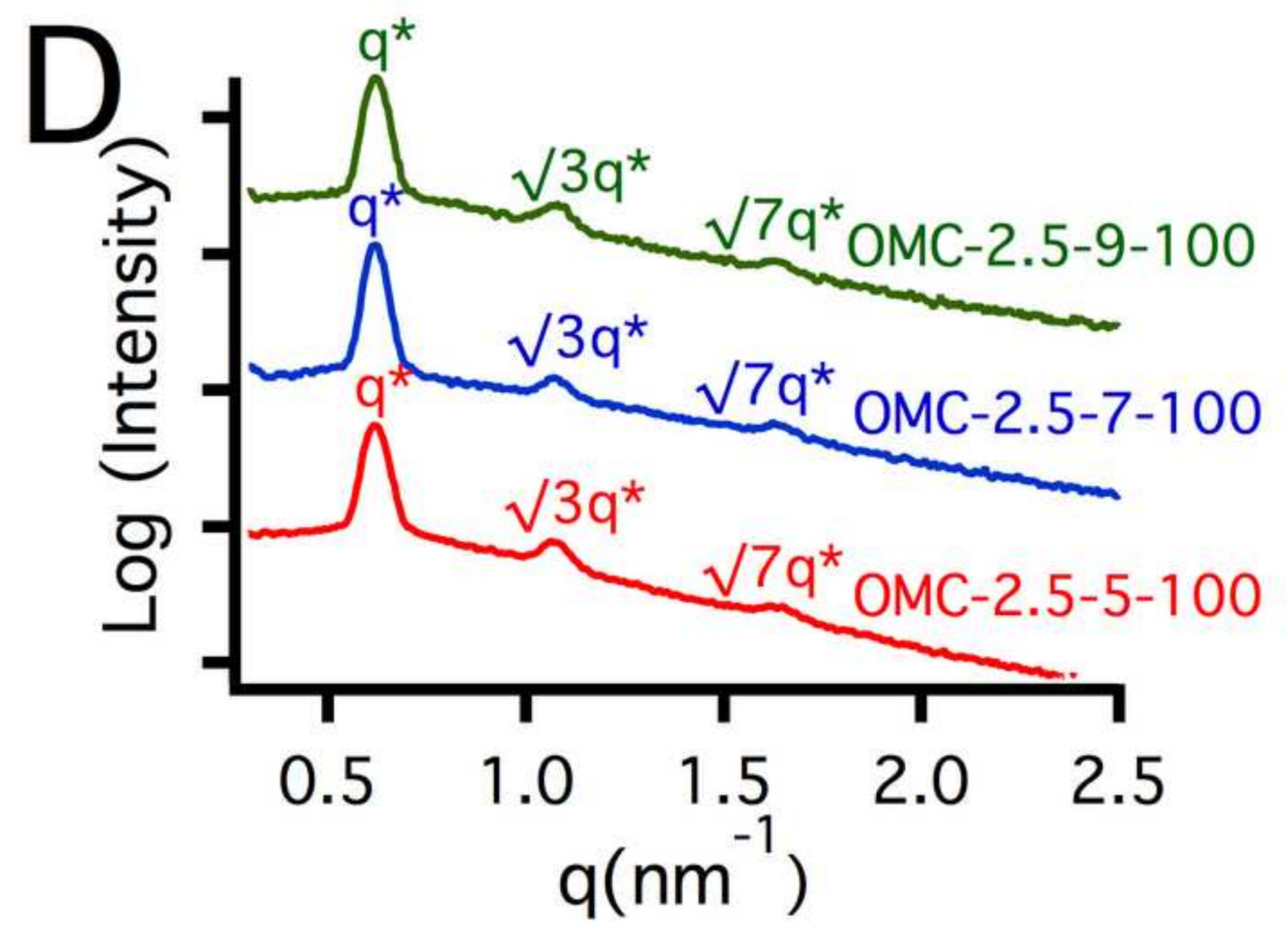




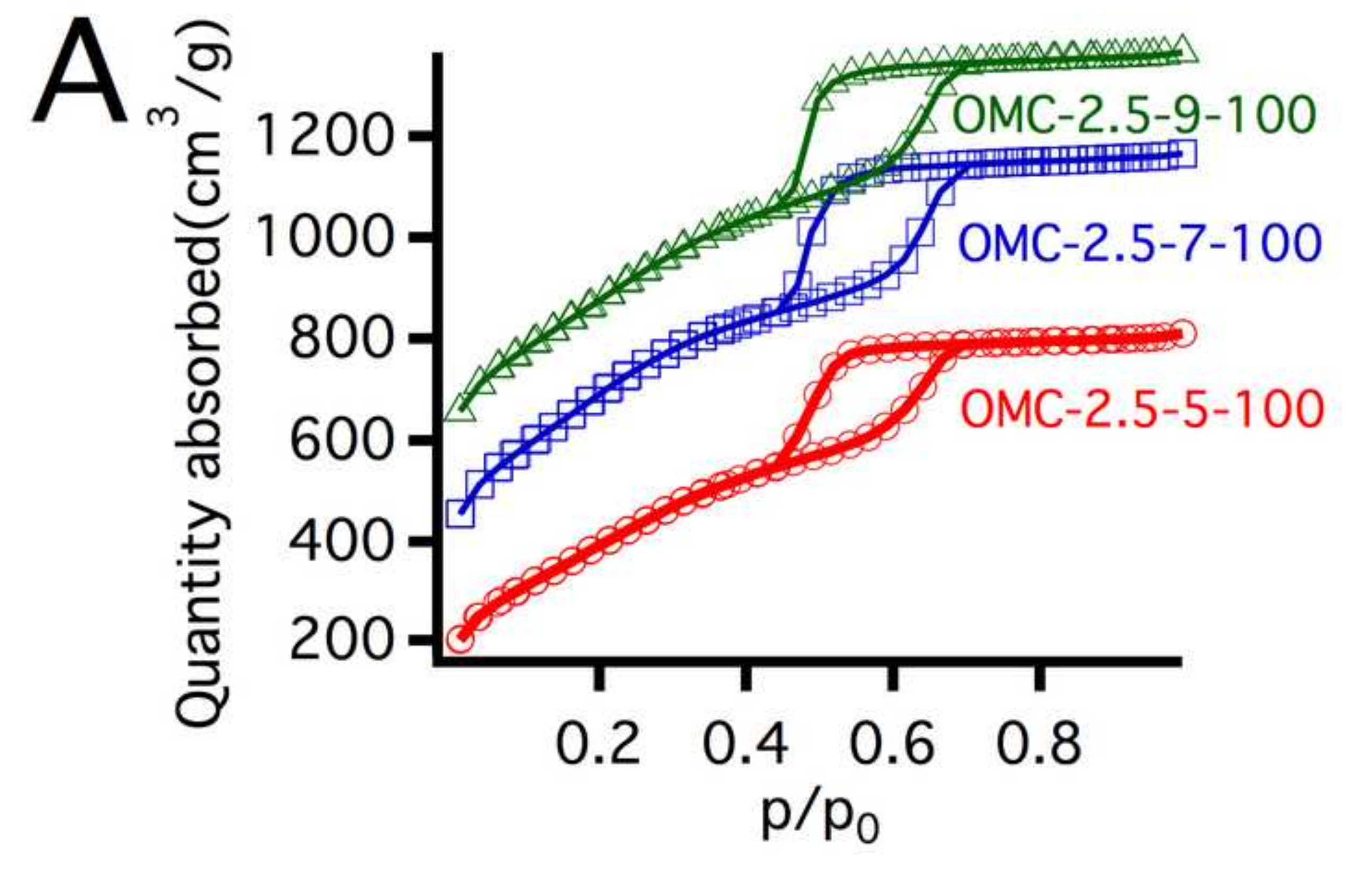



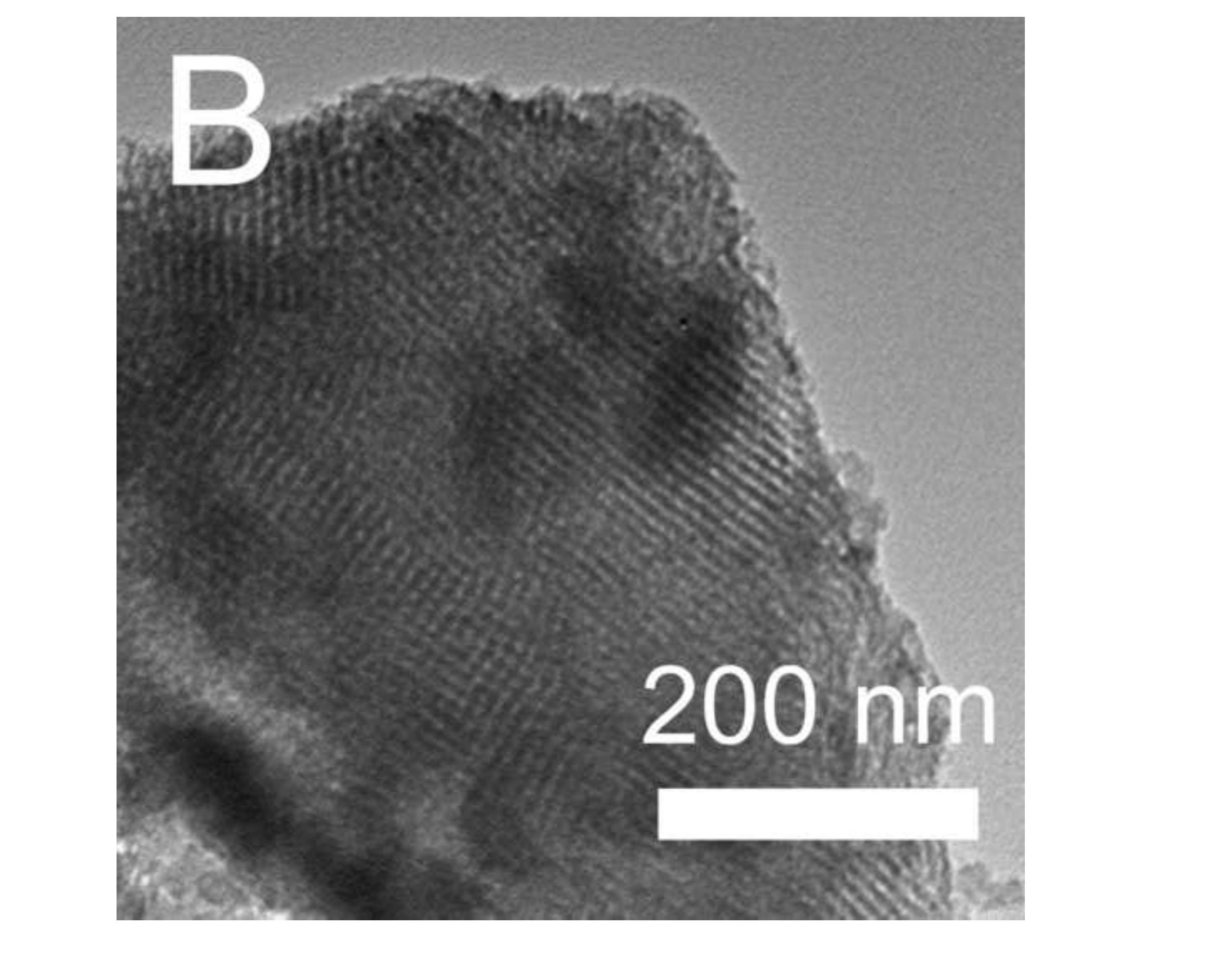

\section{Fig4B}
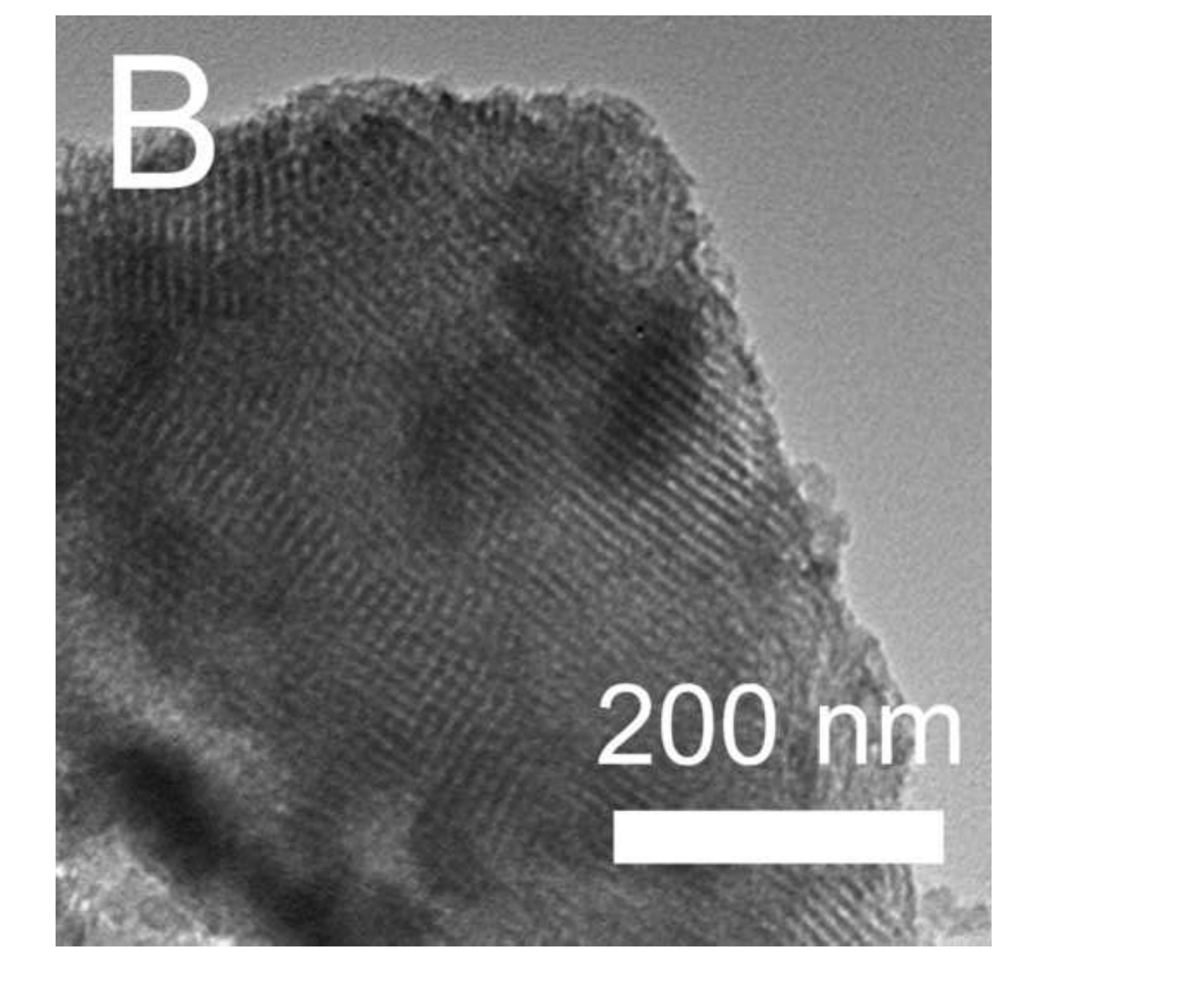


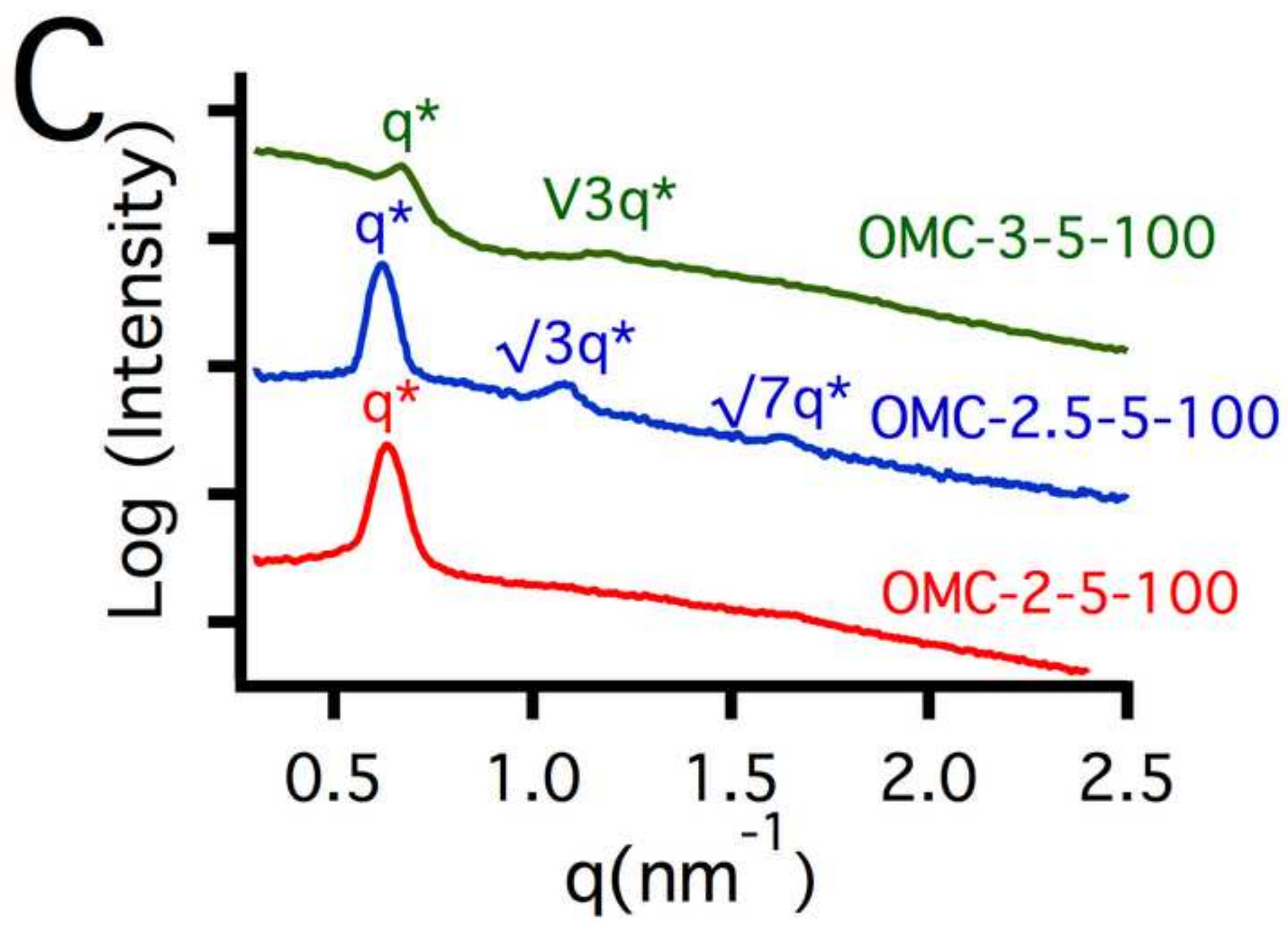




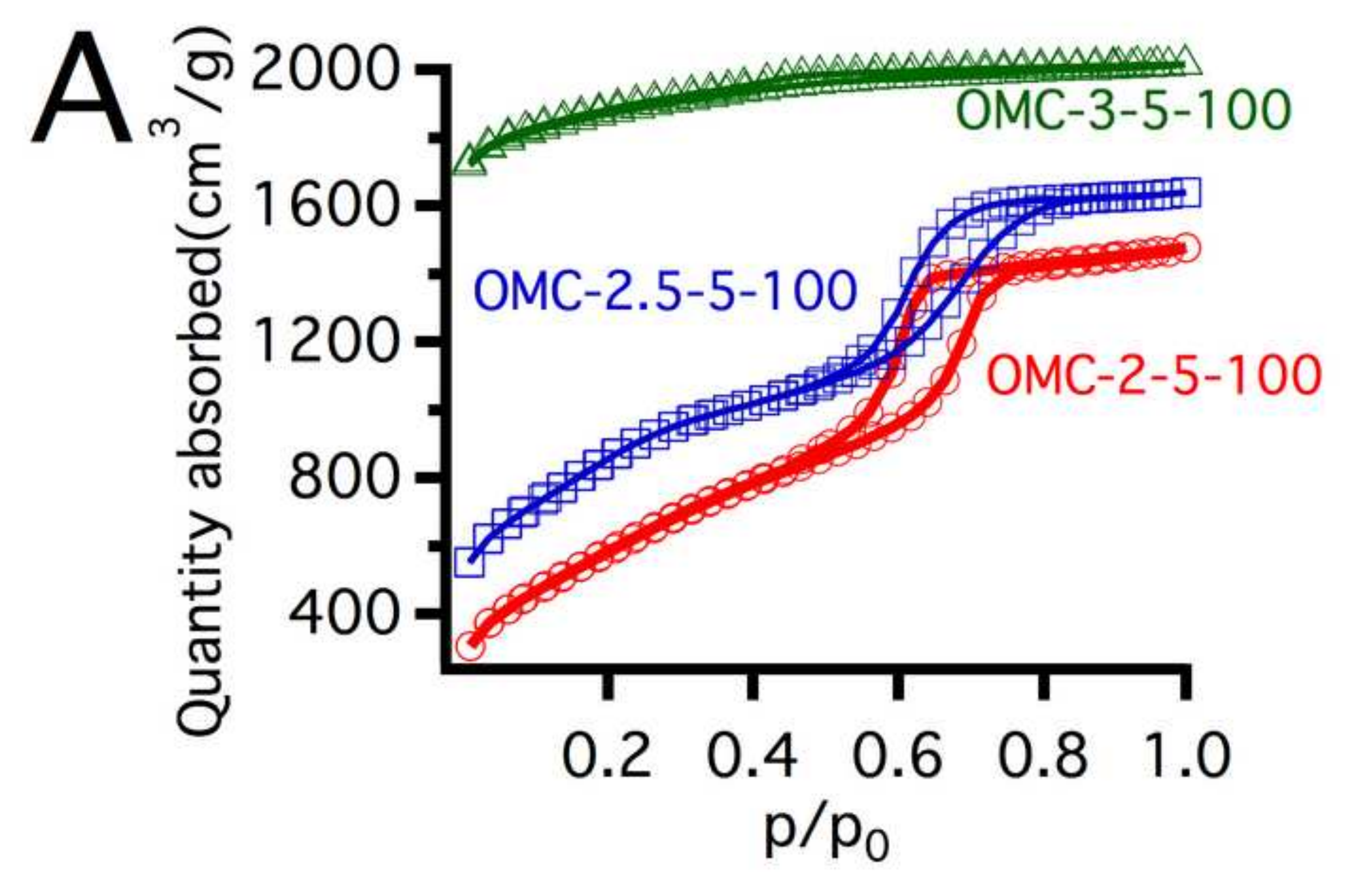




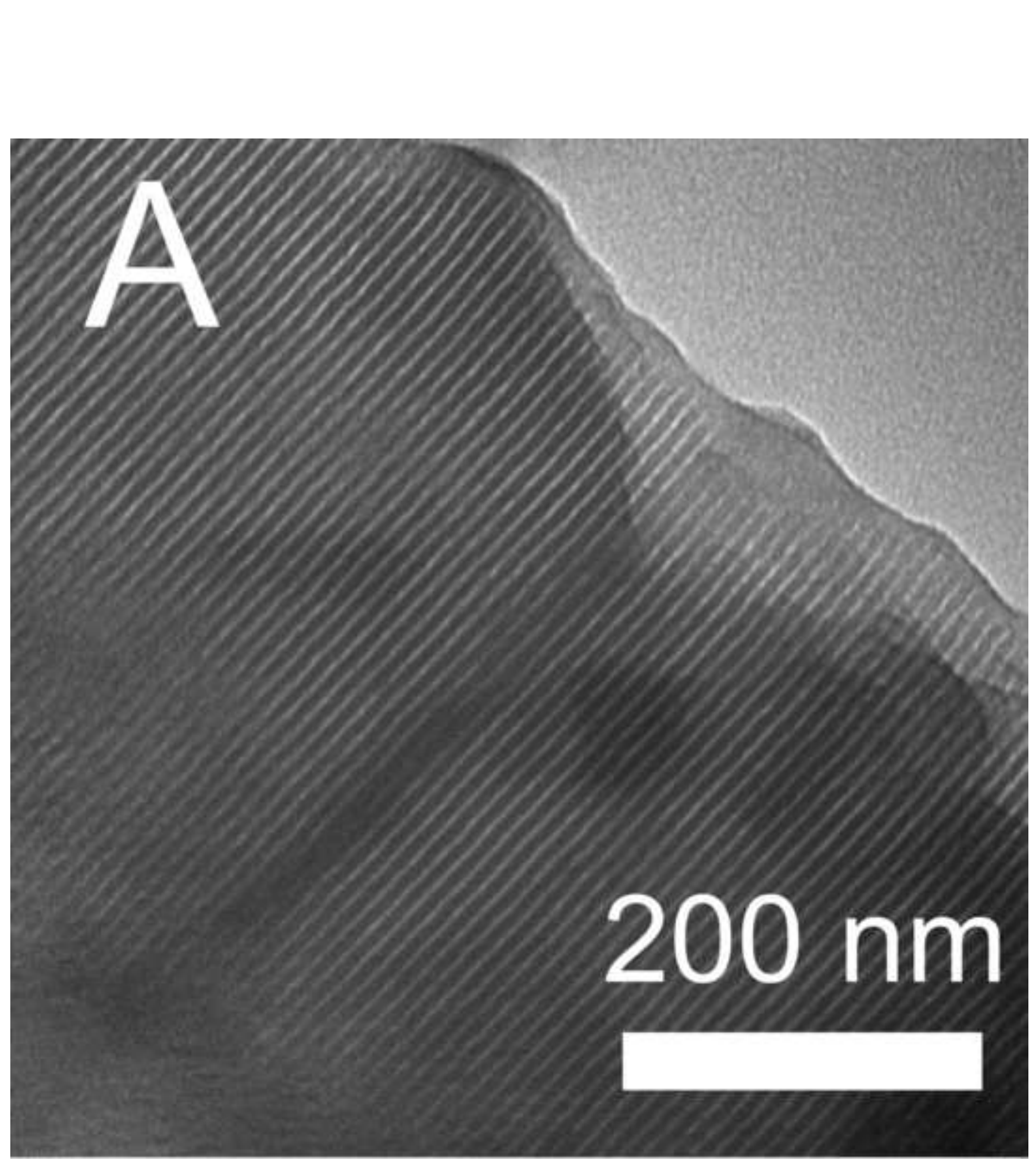

$200 \mathrm{~nm}$

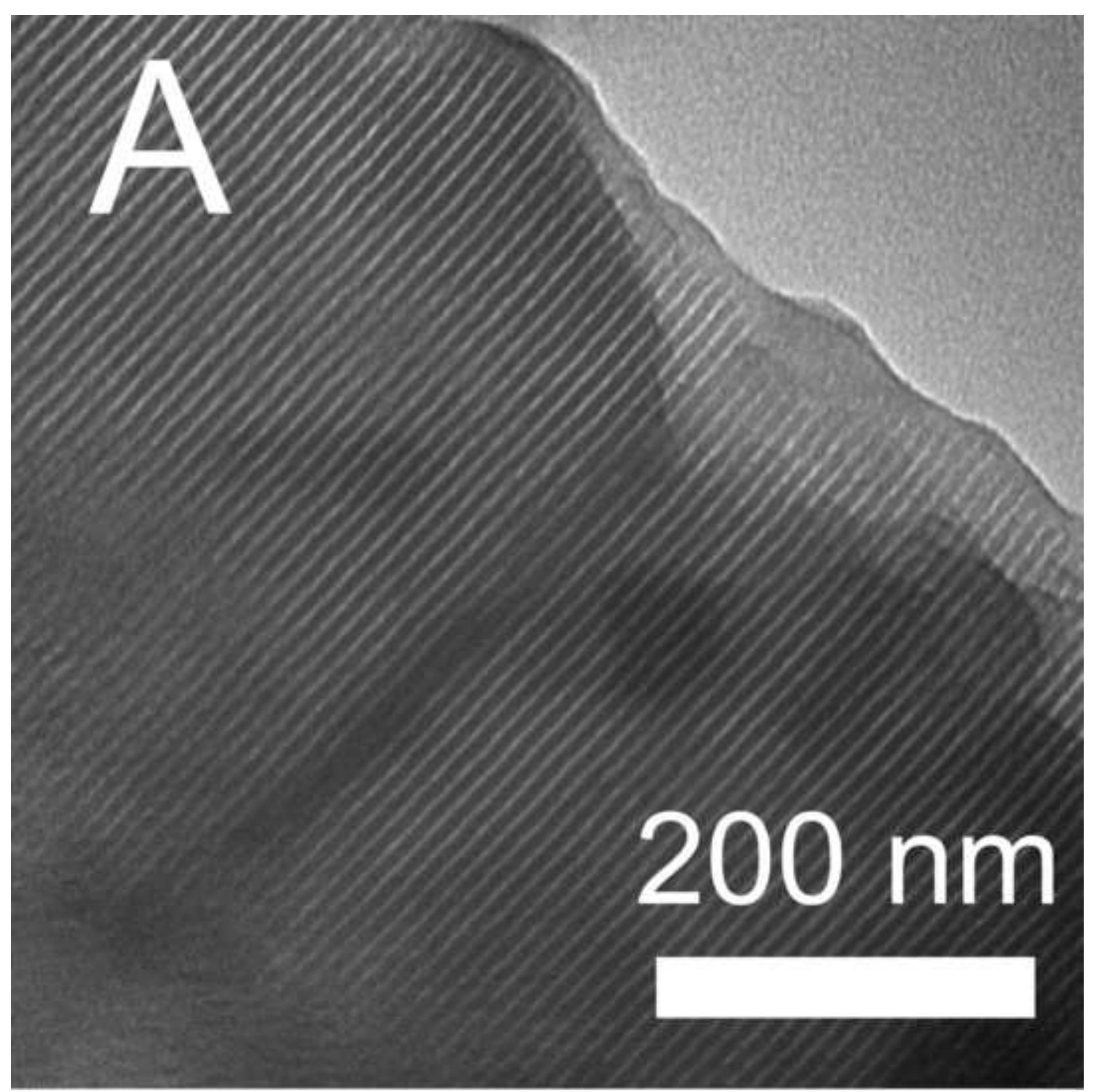

Fig6A

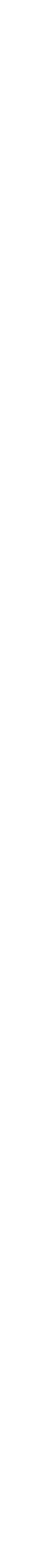
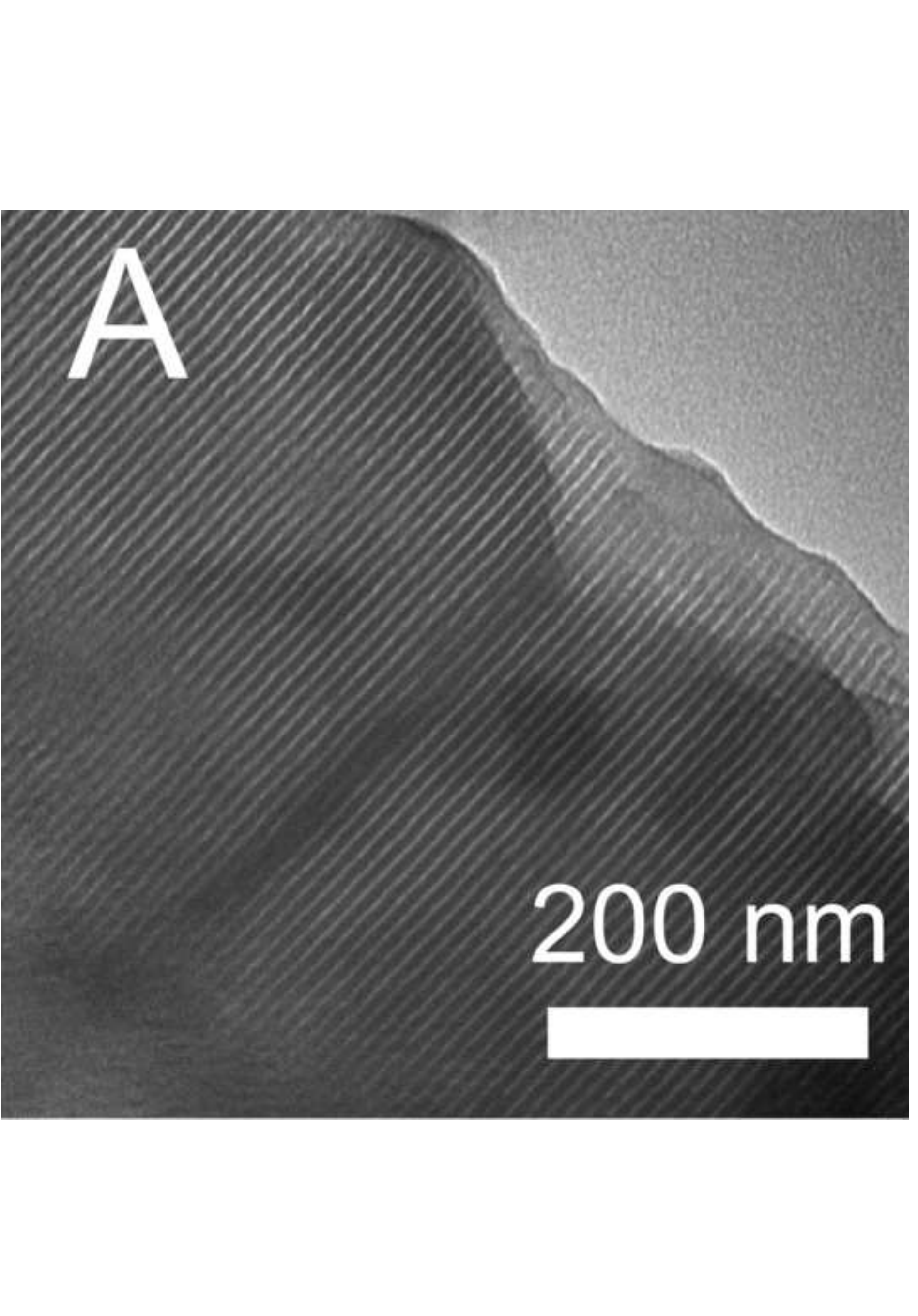


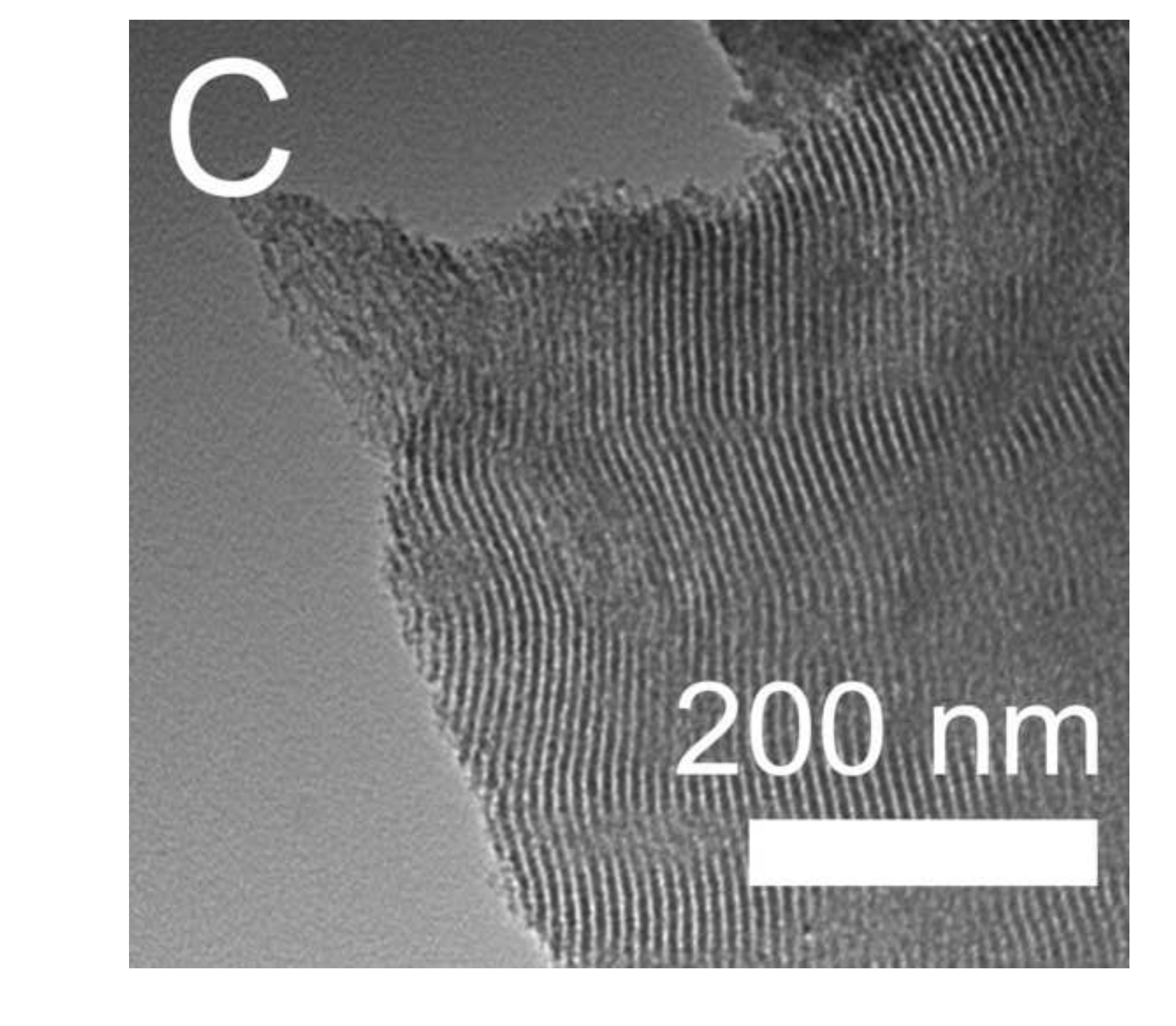

\section{.}
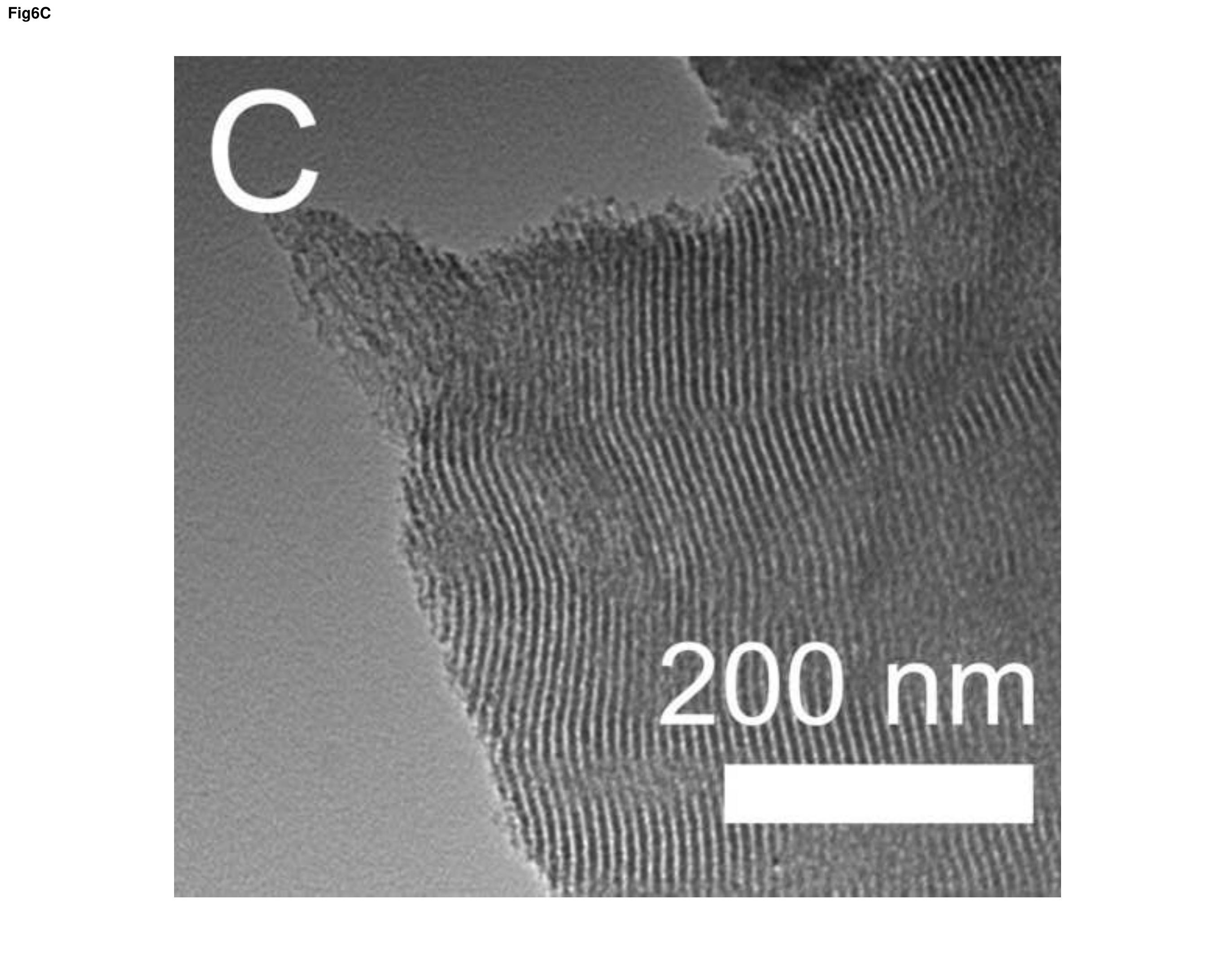


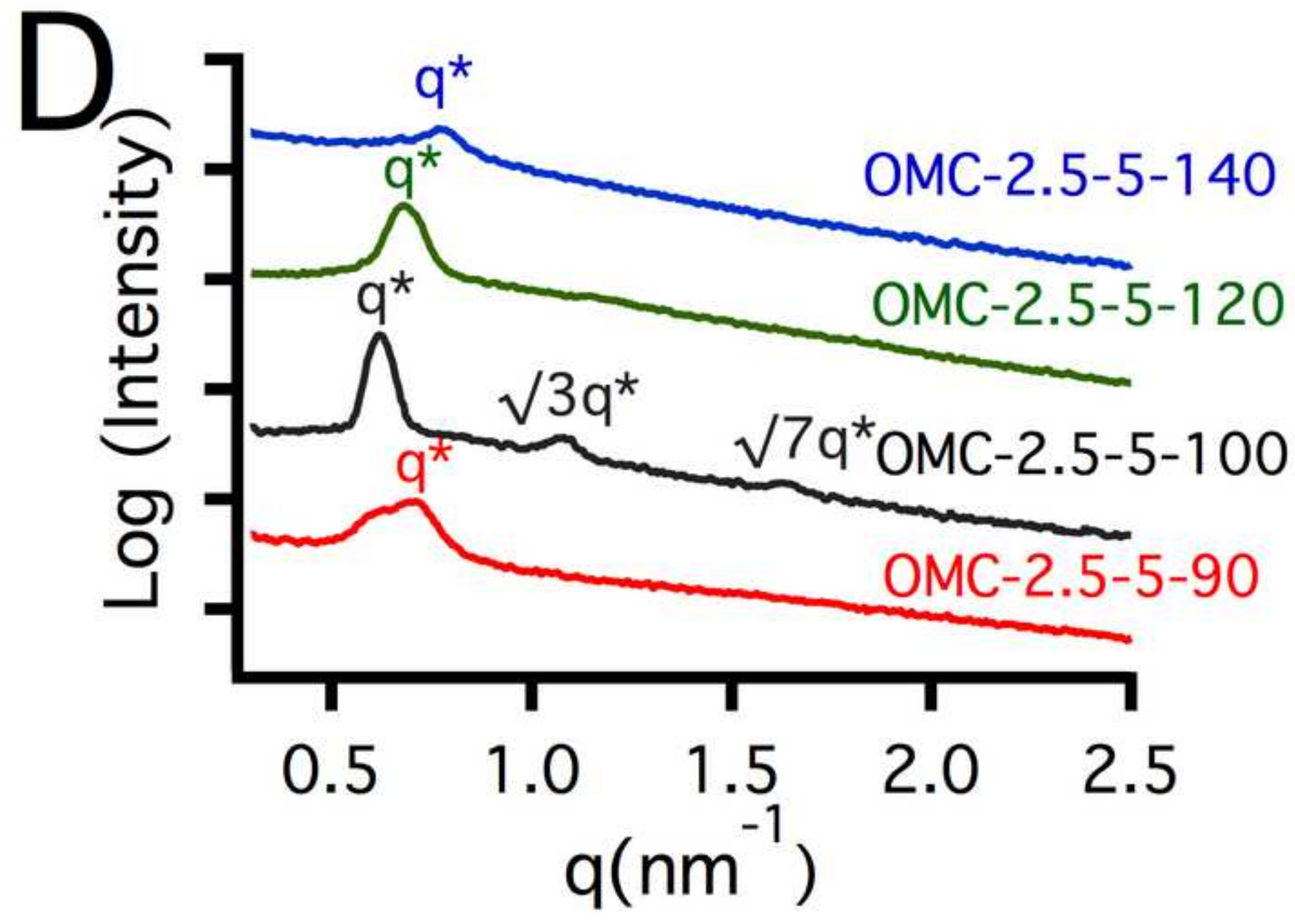

OMC-2.5-5-140

OMC-2.5-5-120

$\sqrt{7} q^{*}$ OMC-2.5-5-100

OMC-2.5-5-90

$\begin{array}{llll}1.0 & 1.5 & 2.0 & 2.5\end{array}$

$\mathrm{q}\left(\mathrm{nm}^{-1}\right)$ 


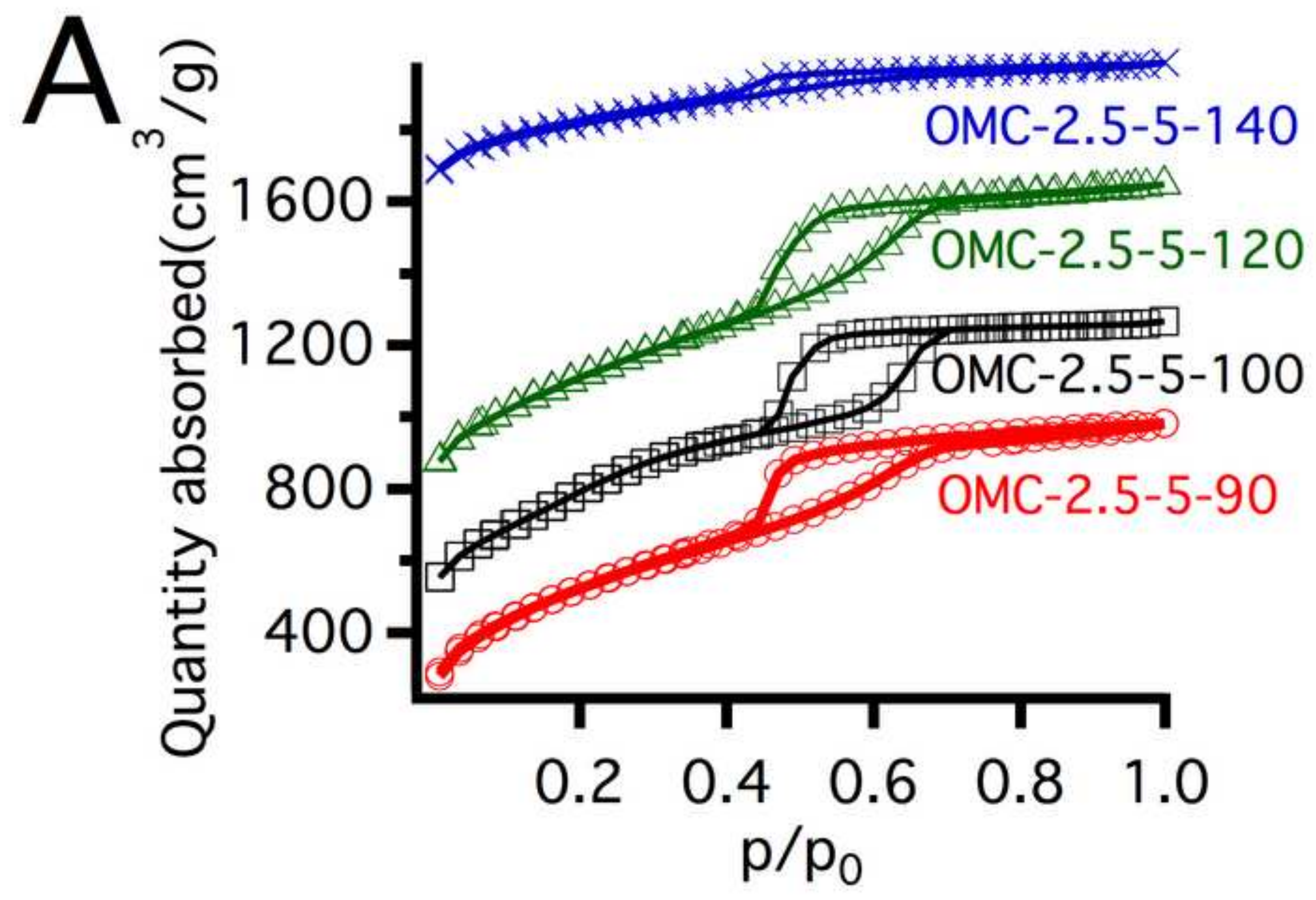




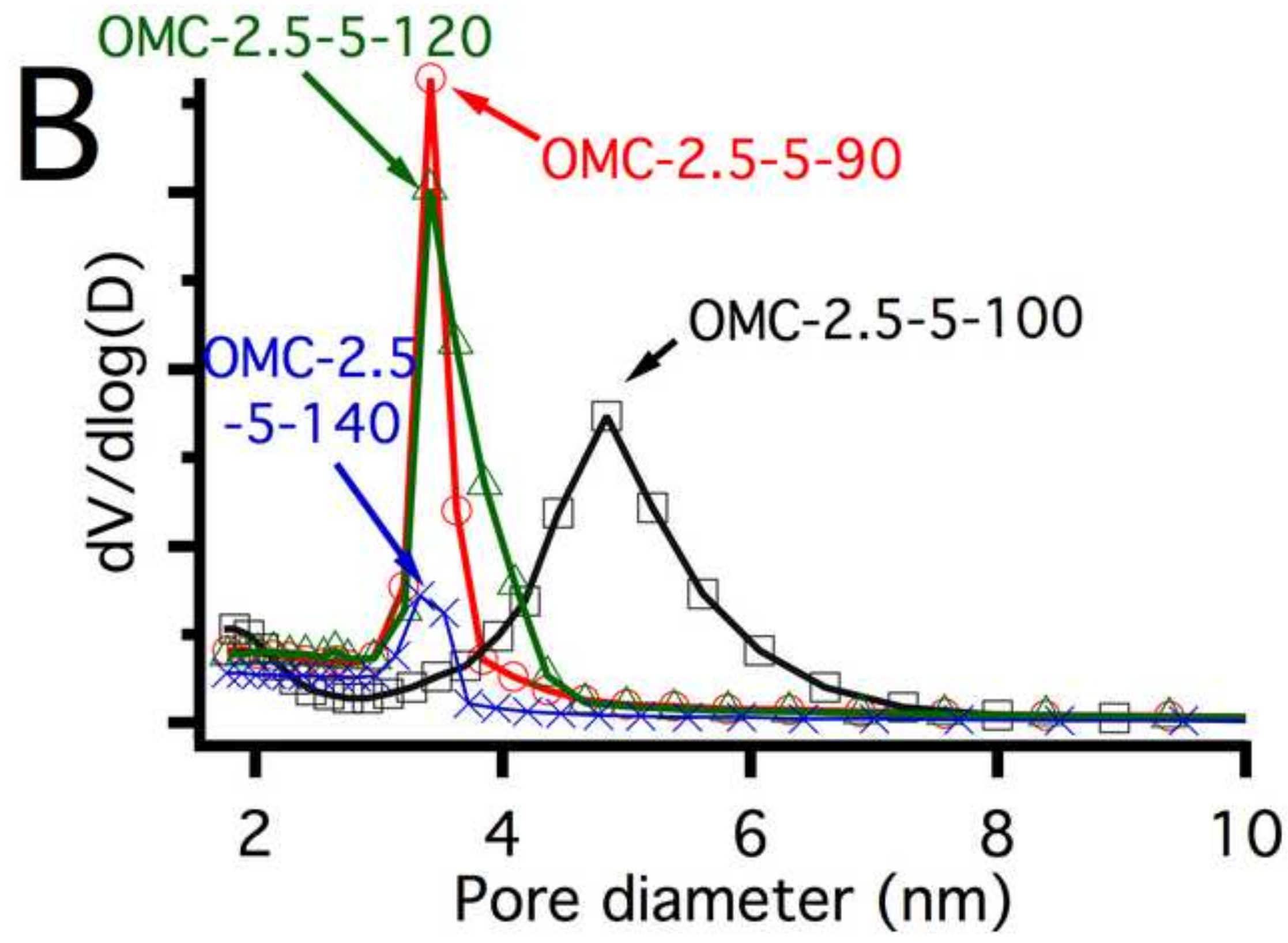

Pore diameter $(\mathrm{nm})$ 


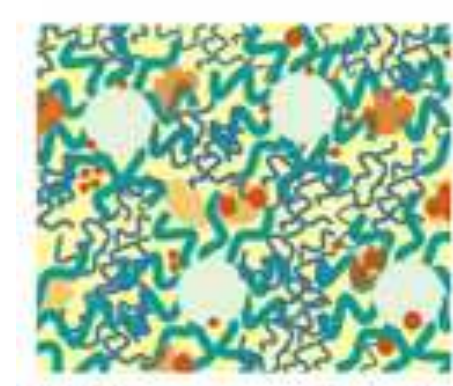

Self-assembled structure
Ethanol content TEOS loading; Crosslink temperature

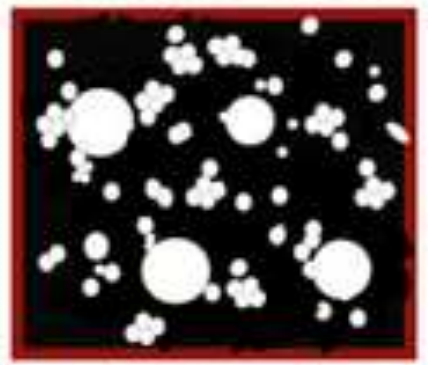

Carbonization
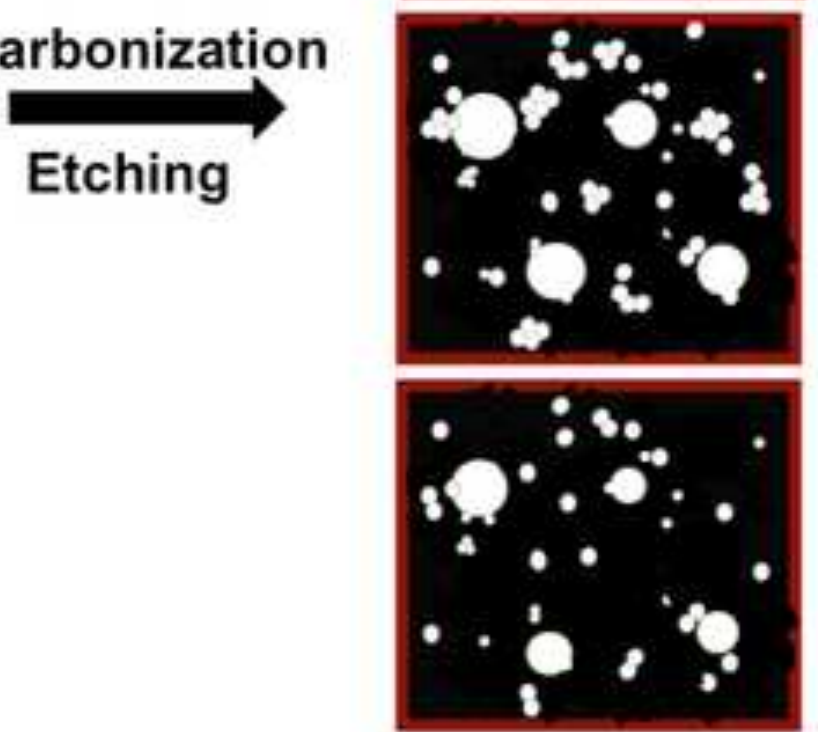

[Ethanol] $\uparrow$

- Lower surface area
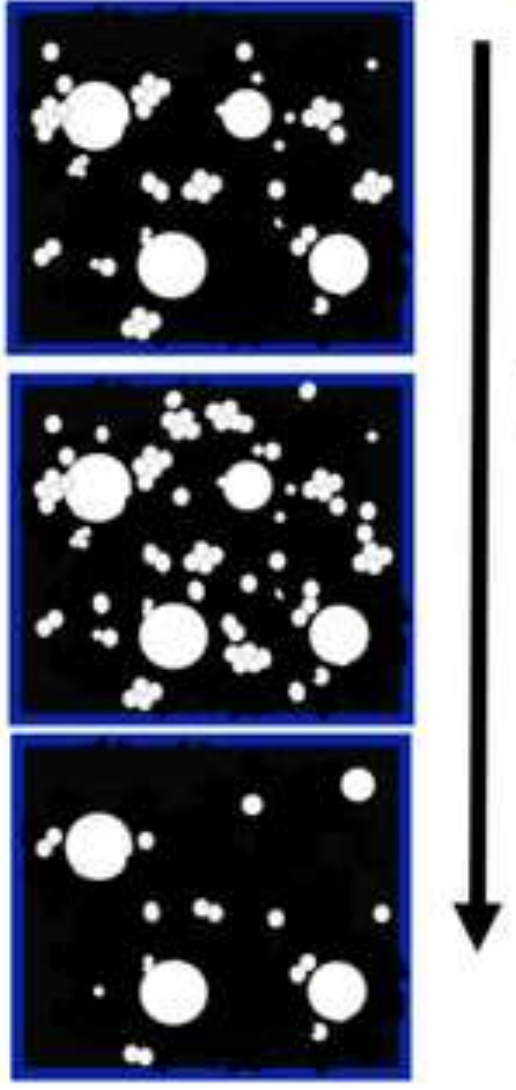

Increasing

Optimized condition: TEOS/resol $=2.5: 1$ at $100^{\circ} \mathrm{C}$

- Smaller pore size

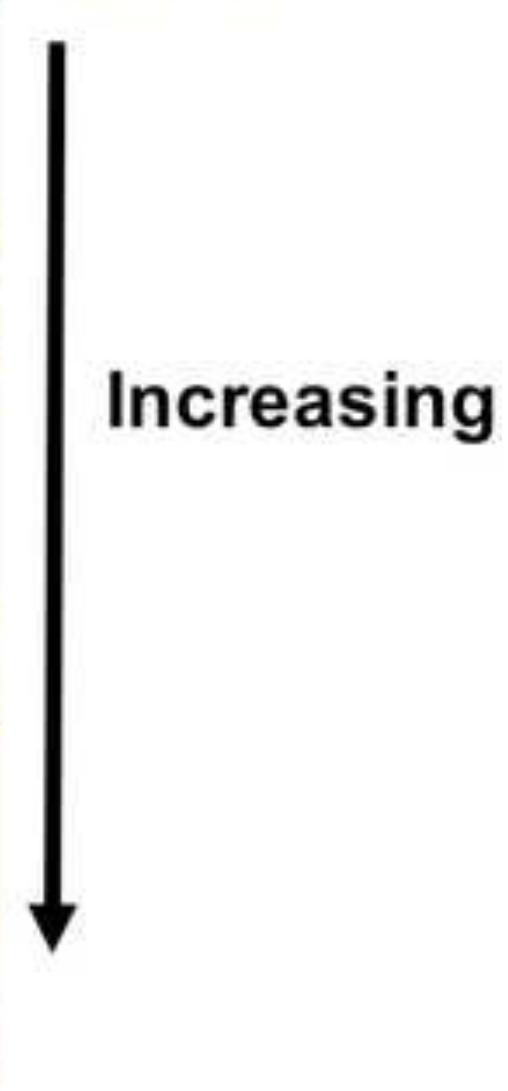

\section{(1)}


A

$0.40-$

○ $0.35-$

$0.30-$

$0.25 \Delta$

$0.20-$
Methylene green

$\Phi$

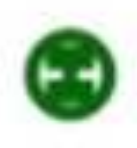

$\Phi$

A 4

Methyl blue

\section{0 \\ 2000 \\ Surface area $\left(\mathrm{m}^{2} / \mathrm{g}\right)$}


Methylene green

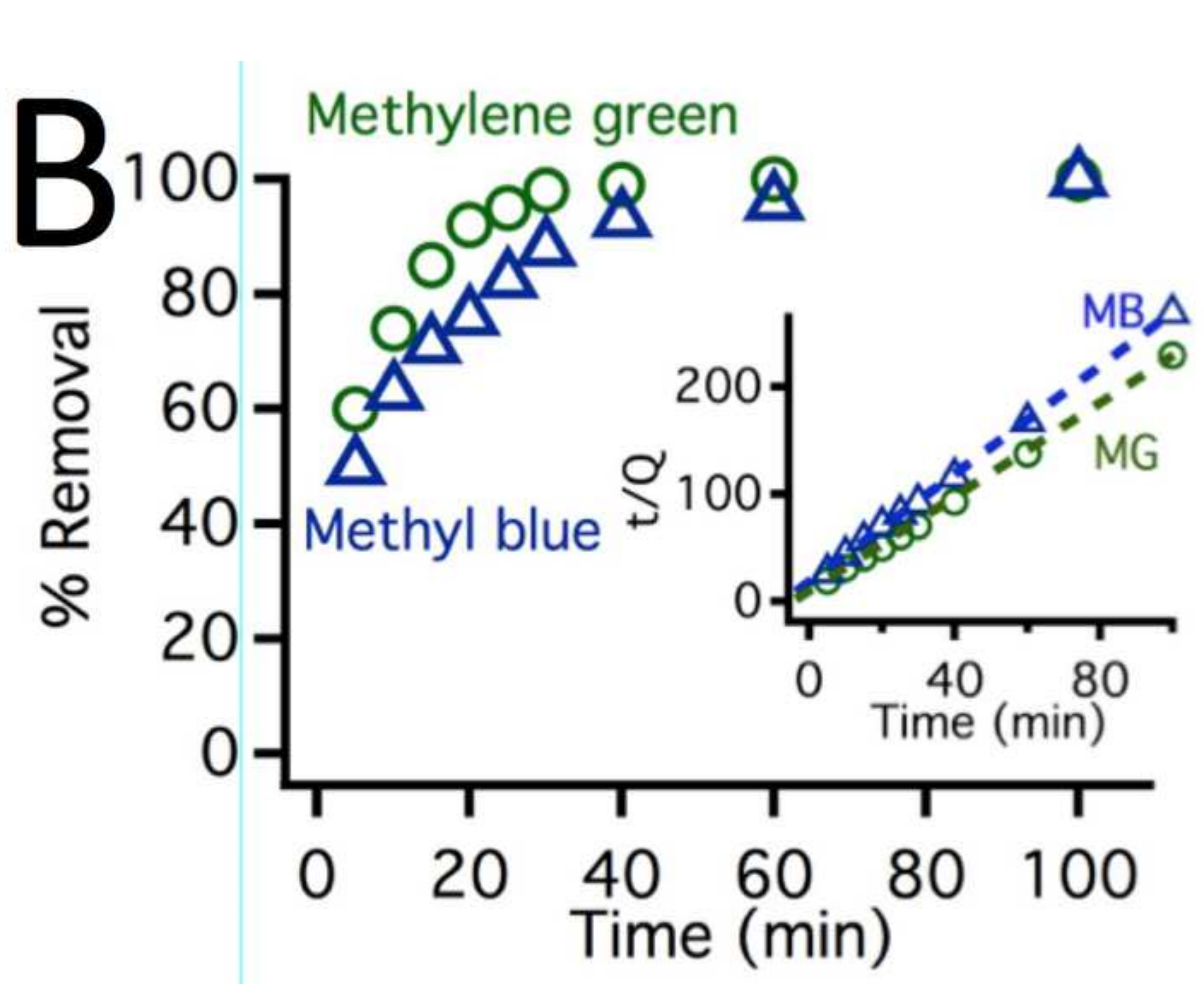

